Article

\title{
Modelling, Testing and Analysis of a Regenerative Hydraulic Shock Absorber System
}

\author{
Ruichen Wang *, Fengshou Gu, Robert Cattley and Andrew D. Ball \\ School of Computing and Engineering, University of Huddersfield, Queensgate, Huddersfield HD1 3DH, UK; \\ f.gu@hud.ac.uk (F.G.); r.cattley@hud.ac.uk (R.C.); a.ball@hud.ac.uk (A.D.B.) \\ * Correspondence: cepe@hud.ac.uk; Tel.: +44-01484-473640
}

Academic Editor: Paul Stewart

Received: 31 March 2016; Accepted: 12 May 2016; Published: 19 May 2016

\begin{abstract}
To improve vehicle fuel economy whilst enhancing road handling and ride comfort, power generating suspension systems have recently attracted increased attention in automotive engineering. This paper presents our study of a regenerative hydraulic shock absorber system which converts the oscillatory motion of a vehicle suspension into unidirectional rotary motion of a generator. Firstly a model which takes into account the influences of the dynamics of hydraulic flow, rotational motion and power regeneration is developed. Thereafter the model parameters of fluid bulk modulus, motor efficiencies, viscous friction torque, and voltage and torque constant coefficients are determined based on modelling and experimental studies of a prototype system. The model is then validated under different input excitations and load resistances, obtaining results which show good agreement between prediction and measurement. In particular, the system using piston-rod dimensions of $50-30 \mathrm{~mm}$ achieves recoverable power of $260 \mathrm{~W}$ with an efficiency of around $40 \%$ under sinusoidal excitation of $1 \mathrm{~Hz}$ frequency and $25 \mathrm{~mm}$ amplitude when the accumulator capacity is set to $0.32 \mathrm{~L}$ with the load resistance $20 \Omega$. It is then shown that the appropriate damping characteristics required from a shock absorber in a heavy-haulage vehicle can be met by using variable load resistances and accumulator capacities in a device akin to the prototype. The validated model paves the way for further system optimisation towards maximising the performance of regeneration, ride comfort and handling.
\end{abstract}

Keywords: suspension; shock absorber; modelling; power regeneration; parameter identification

\section{Introduction}

Vehicle energy harvesting and the improvement of energy efficiency have been of concern for the last two decades. In 2013, road transport accounted for 74\% (39.3 million tonnes of oil equivalent) of the total transport energy consumption in the UK [1]. For commercial vehicles, only $10 \%-20 \%$ of fuel energy is used to propel the vehicle, as most of the energy is wasted by the resistance from road roughness, friction of moving parts and thermal losses, but the kinetic energy loss in the shock absorbers is also one of the notable causes of energy loss in vehicles [2]. Conventional hydraulic shock absorbers convert the vibrational energy into heat to ensure ride comfort and road holding and this heat energy is then lost to the atmosphere.

Since the late 1970s, researchers have analysed the feasibility of regenerative shock absorbers which attempt to recover energy and hence decrease energy consumption whilst assuring high performance and reliability. Karnopp et al. [3] showed that a reduction in vehicle energy consumption can be achieved with energy regeneration in a conventional passive shock absorber, in particular for electric, hybrid electric and fuel cell vehicles. The energy dissipation for a four wheeled vehicle on an irregular road has been estimated to be $200 \mathrm{~W}[4,5]$. A General Motors 'impact' model estimated the average recoverable energy for each wheel to be $100 \mathrm{~W}$ in highway driving conditions, and hence that 
$5 \%$ of the propulsion power could potentially be recovered, as reported by Hsu et al. [6]. By theoretical modelling of road roughness and vehicle dynamics, Zuo and Zhang [7] investigated potential energy regeneration and found that $10-400 \mathrm{~W}$ can be recovered from a conventional shock absorber design at a driving speed of 60 miles per hour ( $\mathrm{mph}$ ) on equivalent USA Class B and C roads, and up to $1600 \mathrm{~W}$ on bad roads. Particularly, approximate power potential of 1-10 kW can be regenerated in light/heavy-duty vehicles, railways and buses under different road conditions [8]. The regenerative power techniques can increase the fuel efficiency of $1 \%-4 \%$ in a traditional vehicle and up to $8 \%$ in electric and hybrid vehicles [9]. As a major part of power consumption in an electric vehicle, the peaks of up to $10 \mathrm{~kW}$ of power can be consumed by all electronic devices such as energy storage, passive/active safety systems, lights and climate control system etc. [10]. These theoretical models and others indicate that suspension system has great potential to achieve the power regeneration purpose in vehicles by recharging the energy storage or repowering the automotive electronic devices.

The oscillation in shock absorbers can be converted into recoverable electricity that can power other devices or recharge the battery by means of a rotary or linear electromagnetic motor. Suda and Nakano et al. [11,12] applied two linear DC motors to improve ride comfort by self-powered active control. In Nakano's studies, one motor worked as a generator to power the other which acted as an actuator to modify the vibratory to behaviour. Arsem [13] first proposed a ball screw in a vehicle suspension system as a regenerative damper to convert mechanical energy into electricity which can be stored in a battery. Then, Suda et al. [14] demonstrated an electromagnetic damper which is comprised of a DC motor, a planetary gearbox and a ball screw mechanism. The DC motor can rotate in both directions to supply power and hence recover energy. Li et al. [15] proposed a permanent magnetic (PM) generator and a rack and pinion mechanism based system to improve gear transmission and energy harvesting. At $30 \mathrm{mph}, 19 \mathrm{~W}$ on average can be captured by this device. In addition, Zabzehgar [16] proposed a novel energy-regenerative suspension mechanism using an algebraic screw linage mechanism which converts the translational vibration into reciprocating rotary motion to drive the generator through a planetary gearhead. Power regeneration can be achieved by integrating a rotary or linear DC motor into a shock absorber to harvest the vibrational energy directly. However, the regenerative capability in such an approach is limited by the excitation velocity.

To improve translational efficiency and to adapt to high excitation velocities, hydraulic transmission has been proposed to convert linear motion into rotary motion and hence produce electricity by a generator/electric motor. A team of Massachusetts Institute of Technology (MIT) students $[17,18]$ patented an energy-harvesting shock absorber that captured energy resulting from relative motion of a vehicle suspension system. This device employs the reciprocating motion of a cylinder with designed hydraulic circuit so unidirectional fluid is generated to drive the hydraulic motor and generator for more power from bump due to road unevenness. Fang et al. [19] applied a hydraulic electromagnetic shock absorber prototype which includes an external hydraulic rectifier and accumulators, but the energy efficiency was only $16.6 \%$ at $10 \mathrm{~Hz} / 3 \mathrm{~mm}$ harmonic excitation. Although an algorithm based on a quarter-car model has been proposed for a hydraulic electromagnetic shock absorber to estimate the optimal load resistance and the damping ratio for maximising the energy-recyclable power, the nonlinear effects of the hydraulic electromagnetic shock absorber were neglected [20].

$\mathrm{Li}$ and Tse [21] fabricated an energy-harvesting hydraulic damper that directly connects the hydraulic cylinder and the motor and three-stage parameter identification was introduced. However, without considering the nonlinearities of the system parameters and high-frequency noise in the parameter identification process, the parameter assumptions in an electromechanical model are that all parameters are constants, which cannot always be valid. Li et al. [22] designed and fabricated a hydraulic shock absorber prototype with a hydraulic rectifier to characterise and identify the mechanical and electrical parameters of an electromechanical model. Zhang et al. [23] introduced a hydraulic pumping regenerative suspension model for a medium-size sport-utility vehicle (SUV) to estimate optimal regenerative power and hydraulic efficiency. 
To compromise between ride health and safety and energy regeneration, automotive researchers have paid considerable attention to active-regenerative suspension. Zheng and $\mathrm{Yu}$ [24,25] proposed a novel energy-regenerative active suspension. The study focuses on the performance improvement in ride comfort and the energy regeneration from road vibration. The results show that the proposed active suspension with control method would be a feasible approach for a better trade-off between active control and energy regeneration. Furthermore, $\mathrm{Xu}$, Tucker and Guo [26-28] proposed similar approaches and mechanisms as the MIT design to study an active shock absorber for energy regeneration. Afterwards, the dynamic features and the feasibility were investigated by theoretical study and preliminary tests. The damping performance, power regeneration and ride health and safety were estimated at this initial stage in an attempt to provide an overview of a regenerative hydraulic suspension system [29].

Although several previous studies utilised a hydraulic rectifier to obtain unidirectional rotation of motion for power regeneration, parametric studies are necessary to enhance the adaptability and stability of such a dynamic model. A prototype must be fabricated for model validation and performance study.

In this paper, a more comprehensive and accurate model of a regenerative hydraulic shock absorber system is proposed which precisely considers the effects of valve flow, fluid bulk modulus variation, accumulator smoothing, the influence of generator features, and losses and leakage of the motor. System parameter identification is used to model the device accurately the proposed model is then validated under different excitations and load resistances. Thereafter, the influences of accumulator capacity are evaluated in terms of the pulsation of the entire system, finally the asymmetric damping characteristics for a conventional hydraulic shock absorber are obtained by adjusting load resistance and accumulator capacity.

The structure of this paper is as follows: In Section 2, the system schematic of a regenerative shock absorber system is proposed. Section 3 describes and analyses the mathematical model of a regenerative shock absorber system which consists of linear oscillations, flow dynamics, rotary motions, and power regeneration processes. Section 4 presents the prototype system development and the determination of the system parameters. The evaluation and comparison between prediction and measurement are then presented in Section 5, and the effects of accumulator capacity are analysed and studied before conclusions are drawn in Section 6 .

\section{System Schematic}

As shown in Figure 1, a schematic design of a regenerative shock absorber which consists of a double-acting hydraulic cylinder, a hydraulic rectifier in the form of four check valves, a hydraulic accumulator, a hydraulic motor, a permanent magnetic generator, pipelines and an oil tank is proposed. The key component of the system is the hydraulic cylinder that represents a traditional shock absorber. In the conceptual design, the end of the shock absorber body is fixed to a stationary frame and the piston rod is connected to a hydraulic actuator which provides oscillatory excitations to represent travel over uneven roads, moving the piston reciprocally. In this paper, the upwards and downwards motions of the piston are described as compression and extension, respectively.

The cylinder was designed to have four ports symmetrically distributed at both sides of the cylinder body. As shown in Figure 1, these ports connect to four check valves which act as a hydraulic rectifier. Through rectification, the fluid in both compression and extension motions passes through the hydraulic motor in a single direction.

The hydraulic motor is directly coupled to the generator via a shaft and driven by the pressurised flow. The hydraulic motor converts the linear motion of the piston into rotary motion by transferring oil from the high-pressure side to the low-pressure side, and the subsequent rotation of the motor shaft drives the generator to produce electricity. Road excitation is simulated by a computer controlled actuator, which can be controlled to input several types of excitations, although in this study a sinusoidal wave is used as the main excitation input. 


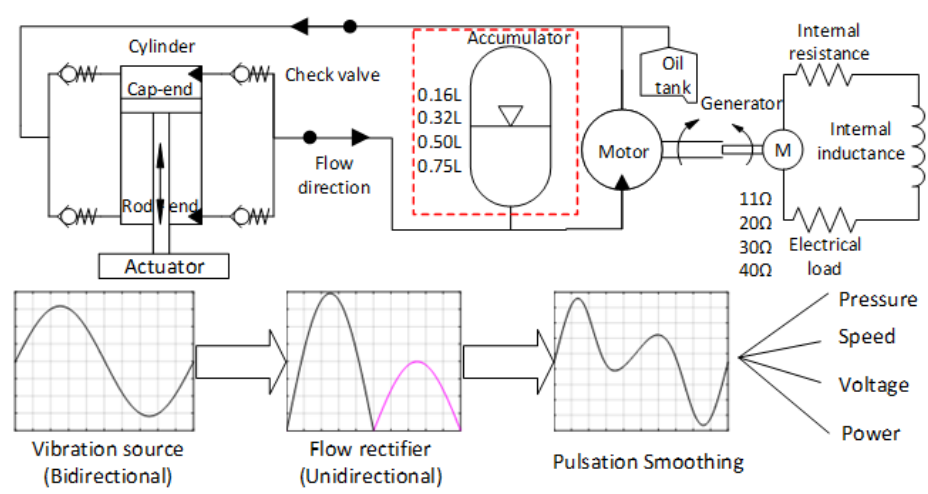

Figure 1. Schematic view of the design concept for a regenerative shock absorber system.

\section{System Modelling and Prototype Development}

Based on the conceptual design of Figure 1, mathematical models have been developed to obtain an accurate understanding of the system dynamics with regard to the hydraulic flow, the rotary motion and the power output. In a practical hydraulic system, the circuits are nonlinear due to valve switching, fluid compressibility, hydraulic losses and leakages, and the influences of such system nonlinearities have been incorporated in the modelling, to obtain accurate predictions of system performance.

\subsection{Hydraulic Flow}

\subsubsection{Vibration Excitation}

For simplicity, the excitation to the system was predefined as a sinusoidal wave, and as such this can be considered as the fundamental element of a more complex and realistic road profile excitation, although the primary motion of a vehicle suspension system often closely resembles such a simple form [30]. The velocity $v(t)$ of this input can be represented:

$$
v(t)=v_{i} \sin (2 \pi f t)
$$

where the velocity amplitude $v_{i}$ is:

$$
v_{i}=2 \pi f S
$$

where $f$ is the frequency, and $S$ the maximum displacement of the piston. As the actuator connects to the piston rigidly, the effective displacement $S_{a}$ of the piston can be expressed as:

$$
S_{\mathrm{a}}=\int v \mathrm{~d} t=S \cos (2 \pi f t)
$$

The volumes of the cap-end chamber $V_{\text {cap }}$ and the rod-end chamber $V_{\text {rod }}$ in the compression and extension strokes can be calculated from the following equations:

$$
\begin{gathered}
\left\{\begin{array}{l}
V_{\text {cap }}=A_{\text {cap }}\left(S_{0}-S_{\mathrm{a}}\right)+V_{\text {ic }}+V_{\text {cyd }} \\
V_{\text {rod }}=A_{\text {rod }}\left(S_{0}+S_{\mathrm{a}}\right)+V_{\text {ir }}+V_{\text {cyd }}
\end{array}, v \geqslant 0\right. \\
\left\{\begin{array}{l}
V_{\text {cap }}=A_{\text {cap }}\left(S_{0}+S_{\mathrm{a}}\right)+V_{\text {ic }}+V_{\text {cyd }} \\
V_{\text {rod }}=A_{\text {rod }}\left(S_{0}-S_{\mathrm{a}}\right)+V_{\text {ir }}+V_{\text {cyd }}
\end{array}, v<0(\text { Extension })\right.
\end{gathered}
$$

where $A_{\text {cap }}$ is the full piston face area, $A_{\text {rod }}$ is the annular area of piston, $V_{\text {ic }}$ is the initial volume of the cap-end chamber, $V_{\text {ir }}$ is the initial volume of the rod-end chamber and $V_{\text {cyd }}$ is the dead volume of the cylinder chambers (referring to the fluid volume in the cylinder chambers at zero position). $S_{0}$ is the initial position of the piston, referring to the middle of the cylinder. 
The areas and velocity of the piston are regarded as known parameters. The cap-end pressure $P_{\text {cap }}$ and the rod-end pressure $P_{\text {rod }}$ act on both sides of the piston to generate compression and extension damping forces $\left(F_{\text {cap }}\right.$ and $\left.F_{\text {rod }}\right)$, which are intended to absorb the vibration from road roughness. Hence, the damping force is directly proportional to the pressure output from the shock absorber, meaning that the piston forces can expressed as:

$$
F_{\text {cap }}=P_{\text {cap }} A_{\text {cap }} \text { and } F_{\text {rod }}=P_{\text {rod }} A_{\text {rod }}
$$

where $F_{\text {cap }}$ is the compression piston force and $F_{\text {rod }}$ is the extension piston force.

To investigate the capability of power regeneration, the power of the piston motion is considered as the total input power as follows:

$$
P_{\text {in }}=P_{\text {cap }} A_{\text {cap }}|v(t)|+P_{\text {rod }} A_{\text {rod }}|v(t)|
$$

where $P_{\text {in }}$ is the total input power of the piston motion, and $|v(t)|$ denotes the instantaneous velocity of the piston.

However, the reciprocating motion of the piston forced by the predefined excitation can generate the damping force and input power. The fluid will pass through the check valves to rectify the flow and then convert linear motion into unidirectional flow in the pipeline.

\subsubsection{Flow across Check Valves}

Figure 2 shows the processes of fluid flows in the compression and extension strokes. The effect of the check valves is to rectify the cylinder flows $Q_{\text {cout }}$ and $Q_{\text {rout }}$ from the cap-end and rod-end chambers, hence the flow into the pipelines can be calculated based on Bernoulli's principle according to:

For flow from the shock absorber :

$$
\left\{\begin{array}{l}
Q_{\text {cout }}=C_{\mathrm{d}} A_{\mathrm{cv}} \operatorname{sgn}\left(P_{\mathrm{cap}}-P_{\mathrm{m}}-P_{\mathrm{cv}}\right) \sqrt{\frac{2\left|P_{\mathrm{cap}}-P_{\mathrm{m}}-P_{\mathrm{cv}}\right|}{\rho}}, P_{\mathrm{cap}}>\left(P_{\mathrm{m}}+P_{\mathrm{cv}}\right) \\
Q_{\mathrm{cout}}=0, P_{\mathrm{cap}} \leqslant\left(P_{\mathrm{m}}+P_{\mathrm{cv}}\right) \\
Q_{\text {rout }}=C_{\mathrm{d}} A_{\mathrm{cv}} \operatorname{sgn}\left(P_{\mathrm{rod}}-P_{\mathrm{m}}-P_{\mathrm{cv}}\right) \sqrt{\frac{2\left|P_{\mathrm{rod}}-P_{\mathrm{m}}-P_{\mathrm{cv}}\right|}{\rho}}, P_{\mathrm{rod}}>\left(P_{\mathrm{m}}+P_{\mathrm{cv}}\right) \\
Q_{\text {rout }}=0, P_{\mathrm{rod}} \leqslant\left(P_{\mathrm{m}}+P_{\mathrm{cv}}\right)
\end{array}\right.
$$

For flow returen to the shock absorber :

$$
\left\{\begin{array}{l}
Q_{\text {cin }}=C_{\mathrm{d}} A_{\mathrm{cv}} \operatorname{sgn}\left(P_{\mathrm{r}}-P_{\text {cap }}\right) \sqrt{\frac{2\left|P_{\mathrm{r}}-P_{\text {cap }}\right|}{\rho}}, P_{\mathrm{r}}>P_{\text {cap }} \\
Q_{\text {cin }}=0, P_{\mathrm{r}} \leqslant P_{\text {cap }} \\
Q_{\text {rin }}=C_{\mathrm{d}} A_{\mathrm{cv}} \operatorname{sgn}\left(P_{\mathrm{r}}-P_{\text {rod }}\right) \sqrt{\frac{2\left|P_{\mathrm{r}}-P_{\text {rod }}\right|}{\rho}}, P_{\mathrm{r}}>P_{\text {rod }} \\
Q_{\text {rin }}=0, P_{\mathrm{r}} \leqslant P_{\text {rod }}
\end{array}\right.
$$

The flows for returning oil to refill the two cylinder chambers, $Q_{\text {cin }}$ and $Q_{\text {rin }}$ are shown in Equation (9), where $C_{\mathrm{d}}$ is the discharge coefficient, $A_{\mathrm{cv}}$ is the area of the effective check valve port, $P_{\mathrm{cv}}$ is the pre-load pressure of the check valves, $P_{\text {cap }}, P_{\text {rod }}$ and $P_{\mathrm{m}}$ represent the pressures at the high pressure side of the motor for the cap-end chamber, the rod-end chamber and the motor inlet respectively. $\rho$ is the density of hydraulic fluid. $P_{\mathrm{r}}$ is the total return pressure in the low-pressure side, it is the sum of the return pressures to the cylinder chambers (cap-end chamber: $P_{\text {cin }}$ and rod-end chamber: $\left.P_{\text {rin }}\right)$ during the compression and extension: $P_{\mathrm{r}}=P_{\text {cin }}+P_{\text {rin }}$.

Considering the compressibility of hydraulic fluid with the effective bulk modulus in variable chambers, the pressures out of the cylinder chambers during the compression and the extension strokes can be described:

$$
\frac{\mathrm{d} P_{\text {cap }}}{\mathrm{d} t}=\frac{\beta_{\text {cap }}\left(A_{\text {cap }} v(t)-Q_{\text {cout }}+Q_{\text {cin }}\right)}{V_{\text {cap }}}(\text { Compression })
$$




$$
\frac{\mathrm{d} P_{\text {rod }}}{\mathrm{d} t}=\frac{\beta_{\text {rod }}\left(A_{\text {rod }}(-v(t))-Q_{\text {rout }}+Q_{\text {rin }}\right)}{V_{\text {rod }}}(\text { Extension })
$$

where $\beta_{\text {cap }}$ and $\beta_{\text {rod }}$ are the effective bulk modulus values for the cap-end and rod-end chambers.

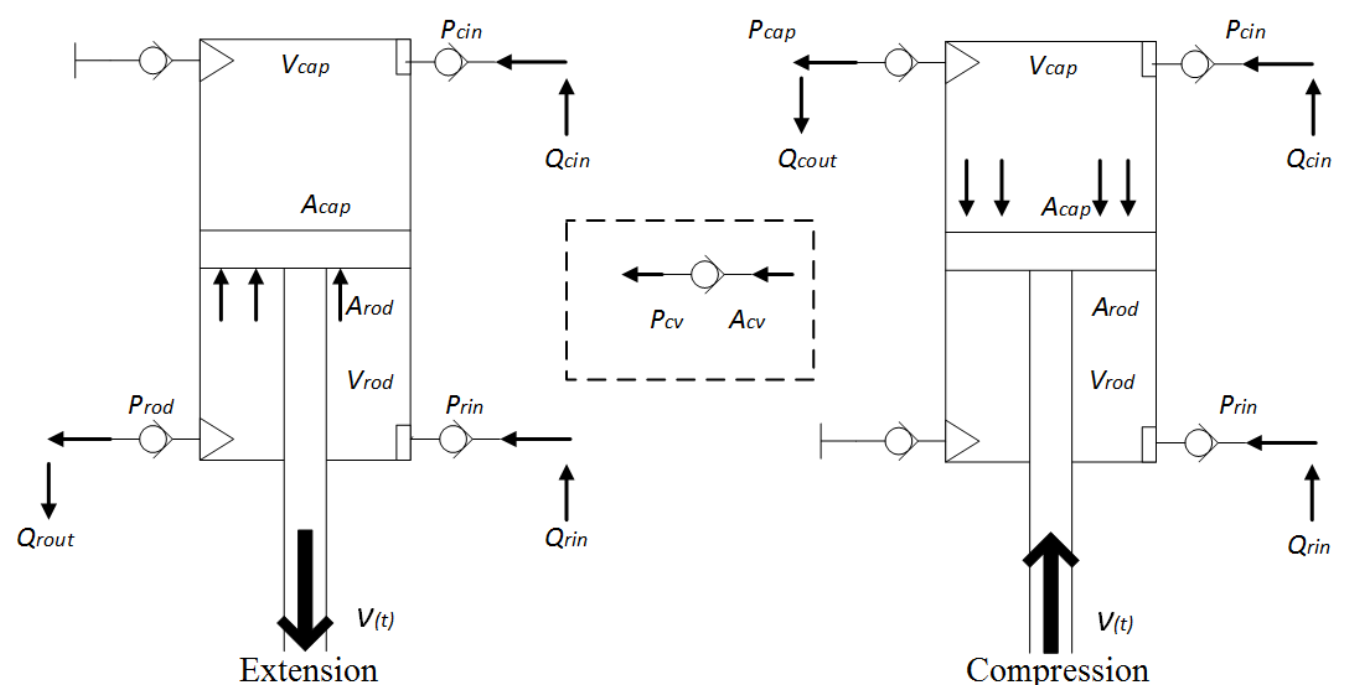

Figure 2. The schematic view of fluid flows in shock absorber body and hydraulic rectifier.

With the motion of the piston, the pressurised fluid passes through a set of check valves, the rectified unidirectional flow is then moved forward to experience the smoothing effect of the accumulator before passing through the hydraulic motor.

\subsubsection{Gas-Charged Accumulator Flow}

In a damper comprised of a single rod cylinder, the flows associated with identical compression and extension movement are inevitably different because of the differing piston areas, and this causes additional fluctuations in the flow rate and pressure experienced by the motor. To minimise this effect, this subsection explores the use of a gas-charged accumulator. Initially, the gas chamber is pre-charged to pressure $P_{\mathrm{pc}}$. The gas-charged accumulator is considered to be in one of three stages for calculation purposes; fully charged, partially charged and fully discharged. Its state depends on the instantaneous accumulator port pressure variation, the flow rate $Q_{\mathrm{acc}}$ and the pressure $P_{\mathrm{f}}$ of the fluid in the accumulator. The effects of the gas-charged accumulator are reflected by the changing volume in fluid chambers $V_{\mathrm{f}}$, and so the pressure and volume variation of accumulator fluid can be written as:

$$
\begin{aligned}
& \text { Accumulator fluid volume : } \\
& \begin{cases}V_{\mathrm{f}}=0 & , P_{\mathrm{f}} \leqslant P_{\mathrm{pc}} \\
V_{\mathrm{f}}=V_{\mathrm{c}}\left(1-\frac{P_{\mathrm{pc}}}{P_{\mathrm{f}}}\right)^{(1 / k)} & , P_{\mathrm{f}}>P_{\mathrm{pc}}\end{cases} \\
& \frac{\mathrm{d} P_{\mathrm{f}}}{\mathrm{d} t}=\frac{-k P_{\mathrm{f}}}{V_{\mathrm{t}}} Q_{\mathrm{acc}}
\end{aligned}
$$

The variation of total volume in accumulator is:

$$
V_{\mathrm{t}}=V_{\mathrm{f}}+V_{\mathrm{agd}}
$$

and the fluid flow to accumulator is:

$$
Q_{\mathrm{acc}}=C_{\mathrm{q}} A_{\mathrm{acc}} \operatorname{sgn}\left(P_{\mathrm{m}}-P_{\mathrm{f}}\right) \sqrt{\frac{2\left|P_{\mathrm{m}}-P_{\mathrm{f}}\right|}{\rho}}
$$


where $V_{\mathrm{t}}$ and $V_{\text {agd }}$ are the total variable volume in the accumulator and the accumulator dead volume respectively, $A_{\text {acc }}$ is the area of the accumulator inlet port and $k$ is the gas specific heat ratio of the gas-charged accumulator. Certain assumptions have been made to simplify the calculations:

(1) The gas-charged accumulator is assumed to be adiabatic, ignoring the heat exchange that happens between the gas and oil under conditions of rapid-cycling.

(2) There are no frictions or thermal losses occurring during the charge/discharge cycles in the accumulator model. When the accumulator is running under variable pressure, thermal losses caused by variation in the gas temperature will inevitably influence gas behaviour.

(3) The pressures in the fluid chamber instead of those in the gas chamber are used for flow rate calculation, which is reasonable because of the transient pressure balance inside the accumulator.

However, Equations (14)-(19) indicate that the volume variation of the accumulator fluid chamber can smooth the flow oscillations and hence help to minimise the instability of the fluid flow. The gas-charged accumulator utilises compressed gas to maintain balance between the fluid chamber and the gas chamber, then to stabilise the flow rate through the motor inlet.

\subsubsection{Flow through the Hydraulic Motor}

With the accumulator mounted upstream of the inlet of the hydraulic motor, the total volume $V_{\mathrm{T}}$ upstream of the motor inlet includes the hydraulic accumulator fluid chamber $V_{\mathrm{f}}$ and the fluid volume of the pipeline $V_{1}$. The pressure loss $P_{\text {loss }}$ in the moving fluid at different flow rates across the pipeline is considered based on the Darcy-Weisbach Equation [31], hence the pressure $\mathrm{d} P_{\mathrm{m}} / \mathrm{d} t$ at the inlet of the hydraulic motor is as follows:

$$
\frac{\mathrm{d} P_{m}}{\mathrm{~d} t}=\frac{\beta_{\mathrm{m}}\left(Q_{\text {cout }}+Q_{\text {rout }}-Q_{\mathrm{m}}-Q_{\mathrm{acc}}\right)}{V_{\mathrm{T}}}
$$

where the volume variation before the motor inlet is:

$$
V_{\mathrm{T}}=V_{\mathrm{f}}+V_{1}
$$

and the pipeline volume is:

$$
V_{1}=A_{\mathrm{p}} L
$$

The internal flow leakage in the motor is considered as a development and a more accurate hydraulic motor flow rate can be expressed [32]:

$$
Q_{\mathrm{m}}=\frac{D_{\mathrm{m}} \omega_{\mathrm{m}}}{2 \pi}+K_{\mathrm{lk}} P_{\mathrm{m}}
$$

using the Hagen-Poiseuille coefficient $K_{\mathrm{HP}}$ [32]:

$$
K_{\mathrm{HP}}=\frac{D_{\mathrm{m}} \omega_{\text {nom }}\left(1-\eta_{\mathrm{V}}\right) \sigma_{\mathrm{nom}} \rho}{P_{\text {nom }}}
$$

and the dynamic viscosity of hydraulic oil is:

$$
\mu=\sigma \rho
$$

Thereafter, the hydraulic motor leakage coefficient is a mathematical expression of the effectiveness of the motor leaking and can be written as follows [32]:

$$
K_{\mathrm{lk}}=\frac{K_{\mathrm{HP}}}{\mu}
$$


with pressure loss in the pipeline of:

$$
P_{\text {loss }}=\frac{32 \sigma L \rho\left(Q_{\text {cout }}+Q_{\text {rout }}\right)}{D_{\mathrm{p}}^{2} A_{\mathrm{cv}}}
$$

where $\beta_{\mathrm{m}}$ is the effective bulk modulus of the motor chamber, $A_{\mathrm{p}}$ is the cross section of area of the pipe, $L$ is the length of the pipe, $D_{\mathrm{m}}$ is the displacement of the hydraulic motor, $\omega_{\mathrm{m}}$ is the shaft speed of the hydraulic motor and generator, $\eta_{v}$ is the volumetric efficiency of the hydraulic motor, $\sigma$ is the kinetic viscosity of the hydraulic oil, $\mu$ is the dynamic viscosity of the hydraulic oil, $\omega_{\text {nom }}$ is the nominal motor angular velocity, $P_{\text {nom }}$ is the nominal motor pressure, $\sigma_{\text {nom }}$ is the nominal kinetic viscosity of the hydraulic oil, $\rho$ is the density of the hydraulic oil, $K_{\mathrm{HP}}$ is the Hagen-Poiseuille coefficient, $K_{\mathrm{lk}}$ is the motor leakage coefficient and $D_{\mathrm{p}}$ is the diameter of the pipe.

\subsection{Rotational Motion}

Due to the pressurised flow $Q_{\mathrm{m}}$, the hydraulic motor will rotate with driving torque $T_{\mathrm{m}}$ according to the following expression [19]:

$$
T_{\mathrm{m}}=\frac{D_{\mathrm{m}}\left(P_{\mathrm{m}}-P_{\text {loss }}\right) \eta_{\mathrm{m}}}{2 \pi}
$$

where $\eta_{m}$ is the mechanical efficiency of the hydraulic motor. To be able to obtain an accurate representation of the rotary motion, a rotational friction torque component $T_{\mathrm{rf}}$ was incorporated as a form of mechanical loss, simplified as follows [33]:

$$
T_{\mathrm{rf}}=C_{\mathrm{v}} \omega_{\mathrm{m}}
$$

where $C_{\mathrm{v}}$ is the viscous friction coefficient, and $\omega_{\mathrm{m}}$ is the shaft speed.

Using Newton's second law of motion, the rotary motion can then be written as:

$$
\frac{\mathrm{d} \omega_{\mathrm{m}}}{\mathrm{d} t}=\frac{T_{\mathrm{m}}-T_{1}-T_{\mathrm{rf}}}{J_{\mathrm{t}}}
$$

where $J_{\mathrm{t}}$ is the moment of inertia of the shaft and $T_{1}$ is the electromagnetic torque (described in Section 3.3).

\subsection{Electrical Power}

In the regenerative power unit of an equivalent DC generator, the electromagnetic torque coefficient $T_{1}$ can be expressed using the torque constant coefficient $k_{\mathrm{T}}$ and the electric current $I$ as follows [20]:

$$
T_{1}=k_{\mathrm{T}} I
$$

and the electromotive force (EMF) $E$ is given by [20]:

$$
E=k_{\mathrm{V}} \omega_{\mathrm{m}}
$$

where $k_{\mathrm{V}}$ is the electromotive voltage constant.

The dynamic model for the equivalent permanent magnetic DC generator depends on Kirchhoff's voltage law [34]. Assuming that the magnet susceptibility at any temperature is constant, as the flux established by the PM poles, the rate of change of current can be expressed as:

$$
\frac{\mathrm{d} I}{\mathrm{~d} t}=\frac{E-\left(R_{\mathrm{in}}+R_{\mathrm{L}}\right) I}{L_{\mathrm{in}}}
$$

where $L_{\text {in }}$ is the internal inductance of the DC generator, which can be calculated based on measured voltages, $R_{\mathrm{L}}$ is the load resistance and $R_{\text {in }}$ is the internal resistance. 
The most intuitive means of quantifying the power regeneration is from the instantaneous power output and the power efficiency. In modelling, the regenerated power output $P_{\text {reg }}$ can be calculated from the $I^{2} R$. In testing, the instantaneous voltage $U=R_{\mathrm{L}} I$ at terminals of the load resistance can be measured to estimate the potential power output, hence an equivalent expression for $P_{\text {reg }}$ can be:

$$
P_{\text {reg }}=I^{2} R_{\mathrm{L}}=\frac{U^{2}}{R_{\mathrm{L}}}
$$

The regenerated power conversion efficiency $\eta_{\text {reg }}$ can be defined as the total efficiency of the hydraulic regenerative shock absorber system which can be considered to be the total efficiency and can be expressed using Equations (27) and (30) as follows:

$$
\eta_{\text {reg }}=\frac{P_{\text {reg }}}{P_{\text {in }}}
$$

\subsection{Fabrication of the Prototype}

The prototype system was fabricated based around a traditional shock absorber/damper from a typical articulated heavy haulage truck. For such a damper, it has been estimated that the potential power that can be recovered is approximately 100-1500 Watts depending on road conditions and truck loading [35]. Based on the schematic shown in Figure 1, key system components were selected as summarised in Table 1. Based on the maximum pressure of the cylinder and the motor torque (Equation (24), it was found that an internal gear hydraulic motor meets the requirements of high torque at low rotational speed.

\begin{tabular}{|c|c|c|c|}
\hline Name & & Specification & \\
\hline Cylinder & $\begin{array}{l}\text { Middle point, } S_{0}=100 \mathrm{~mm} \\
\text { Full stroke, } 200 \mathrm{~mm}\end{array}$ & $\begin{array}{c}\text { Piston area, } D_{\text {cap }}=50 \mathrm{~mm} \\
\text { Annulus area, } D_{\text {rod }}=30 \mathrm{~mm}\end{array}$ & Max. pressure, 200 bar \\
\hline Motor & $\begin{array}{c}\text { Displacement, } \\
D_{\mathrm{m}}=8.2 \mathrm{cc}\left(\mathrm{cm}^{3} / \mathrm{rev}\right)\end{array}$ & Max. speed, $245 \mathrm{rad} / \mathrm{s}$ & Max. power, $<6000 \mathrm{~W}$ \\
\hline Generator & $\begin{array}{l}\text { Internal inductance, } \\
L_{\text {in }}=0.015 \mathrm{H}\end{array}$ & $\begin{array}{l}\text { 2.33 Phase magnetic field, } \\
\text { Built in rectifier, } \\
\text { Max. speed, } 215 \mathrm{rad} / \mathrm{s}\end{array}$ & $\begin{array}{l}\text { Max. current, } 10 \mathrm{~A}, \\
\text { Max. power, }<2450 \mathrm{~W}\end{array}$ \\
\hline Accumulator & Diaphragm accumulator & $\begin{array}{c}\text { Port diameter, } \\
D_{\text {acc }}=12.7 \mathrm{~mm}\end{array}$ & $\begin{array}{l}\text { Pre-charge pressure, } \\
\quad P_{\mathrm{pc}}=20 \mathrm{bar}\end{array}$ \\
\hline Check Valve & $\begin{array}{c}\text { Diameter: } 3 / 8^{\prime} \\
(\approx 9.525 \mathrm{~mm}), \mathrm{BSPP}\end{array}$ & Max. pressure, 350 bar & $\begin{array}{l}\text { Preload pressure, } \\
P_{\mathrm{cv}}=0.7 \text { bar }\end{array}$ \\
\hline Four Post Simulator & Maximum velocity, $1.9 \mathrm{~m} / \mathrm{s}$ & Static load, $550 \mathrm{~kg}$ & Preload, $60 \mathrm{~kg}$ \\
\hline Hose & Hose diameter, $D_{\mathrm{h}}=3 / 8^{\prime}$ & Length, $\mathrm{L}=1 \mathrm{~m}$ & Max. pressure, 800 bar \\
\hline Shock Absorber Oil & Density, $\rho=872 \mathrm{~kg} / \mathrm{m}^{3}$ & Viscosity, $\sigma=22 \mathrm{cSt}$ & - \\
\hline
\end{tabular}

Table 1. The specifications of main components.

A high inertia PM generator was selected to provide the additional benefits of rotational kinetic energy storage and improved the stability of rotary motion, contributing to the efficiency of power regeneration. A diaphragm accumulator suitable for a low volume system was connected in front of the hydraulic motor to smooth the fluid flow on the high-pressure side by reducing the pulsations in pressure. According to the damping forces in a conventional shock absorber for a heavy haulage truck [35], a peak pressure of 35 bar was estimated. The pre-charge pressure in the accumulator was set at $60 \%$ of the working pressure (of $20 \mathrm{bar}$ ) to provide pressure pulsation damping.

According to Equations (20)-(23), low viscosity shock absorber oil was used to minimise the losses in the hydraulic motor and pipework. 


\subsection{Test System and Measurement}

Via trial and error, numerous refinements were made to the prototype system to permit more reliable and accurate simulation. For example, air bubbles in the fluid within the test system lead to changes in oil viscosity and the bulk modulus, consequently, an air vent valve was employed to minimise the volume of air in the hydraulic fluid and to stabilise the bulk modulus of the oil [36] Furthermore, energy is consumed through compression of the spring in the check valve and to minimise this effect, the length of the check valve spring was reduced by one-third to reduce pressure losses and improve dynamic response. In addition, the moving-mass orifices in the check valve were enlarged to allow a greater flow rate and hence to offset valve losses. Finally, based on Equations (19)-(24), the length of the hoses was reduced to minimise pressure losses in the pipelines.

Figure 3 shows how the pressure characteristics of the test system were analysed using two pressure transducers mounted upstream of the diaphragm accumulator port and upstream of the hydraulic motor inlet. A U-shaped micro photo sensor mounted on the shaft coupling was used to measure the shaft speed. An electronic load bank was used to vary the load and a voltage transducer measured the electrical output for analysis of power regeneration and conversion efficiency. All of the measured outputs were fed into a multi-channel data acquisition system which sampled the data at $10 \mathrm{kHz}$ with 14 bit resolution. The measured signals could be observed during experiments in real time to ensure the correct functioning of the test rig.

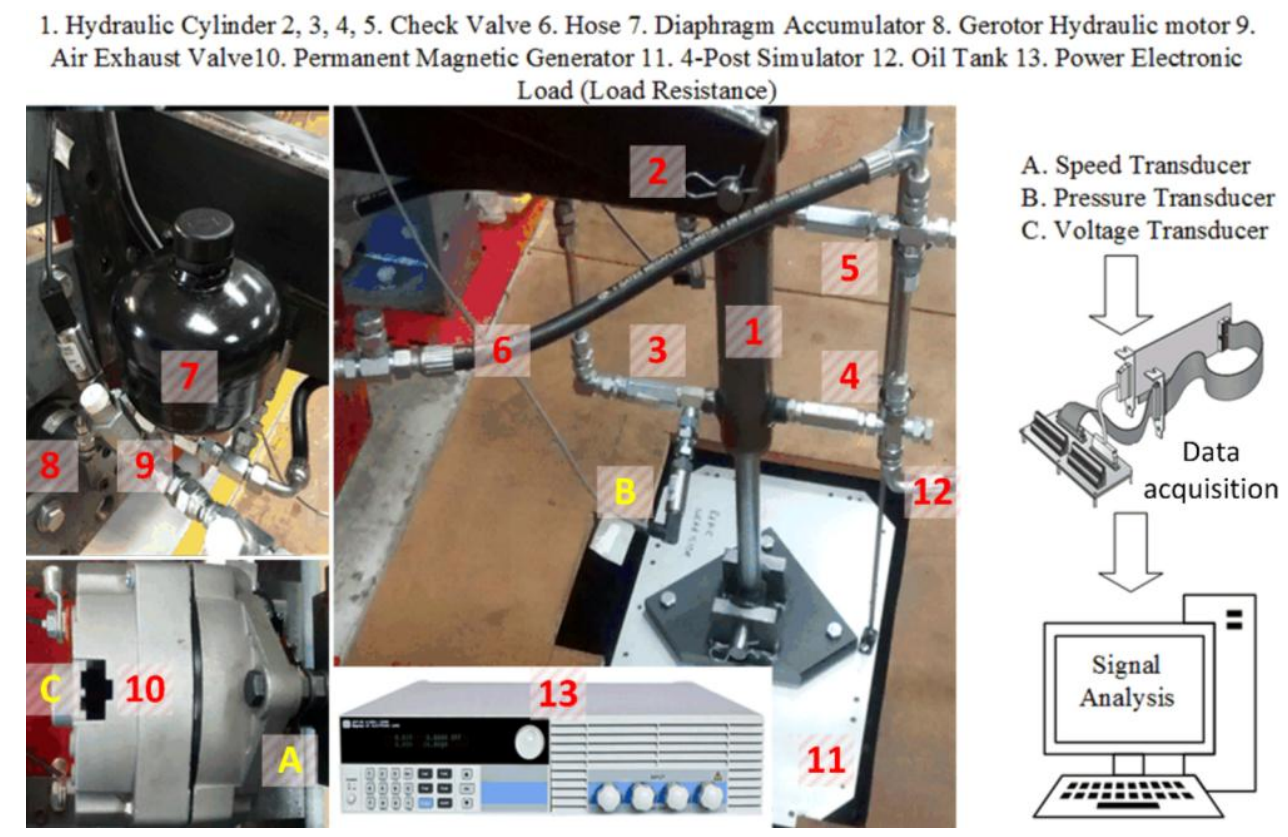

Figure 3. Key components of regenerative shock absorber system.

Real road profiles are often represented as a combination of a number of individual sinusoidal waves but in this study, for simplicity, a single sinusoidal wave representing the fundamental frequency of a road surface was used as the system input for both modelling and testing. Such an approach is not unusual [37], because a single sinusoidal input allows analysis to be performed in a highly accurate manner and hence a general understanding of the dynamic performances of the proposed modelling and prototype system can be obtained. During the experimentation, one corner of a four-post servo-hydraulic ride simulator with a digital control was employed as the source of vibration to excite the shock absorber system. 


\section{Parameter Studies}

According to the setup of this prototype system shown in Figure 3, model parameters associated with geometric dimensions were determined by direct measurement, as shown in Table 2 . The table also shows that discharge and flow coefficients $\left(C_{\mathrm{d}}\right.$ and $\left.C_{\mathrm{q}}\right)$ and the specific heat ratio of air $k$ are parameters where volumes are known.

Table 2. Hydraulic parameters used in modelling.

\begin{tabular}{cccccccc}
\hline Name & Symbol & Value & Unit & Name & Symbol & Value & Unit \\
\hline Accumulator inlet area & $A_{\text {acc }}$ & $1.27 \times 10^{-4}$ & $\mathrm{~m}^{2}$ & Flow coefficient & $C_{\mathrm{q}}$ & 0.7 & - \\
\hline Full piston face area & $A_{\mathrm{cap}}$ & $1.96 \times 10^{-3}$ & $\mathrm{~m}^{2}$ & Specific heat ratio & $k$ & 1.4 & - \\
\hline Check valve area & $A_{\mathrm{cv}}$ & $3.93 \times 10^{-5}$ & $\mathrm{~m}^{2}$ & Cylinder dead volume & $V_{\text {cyd }}$ & $1 \times 10^{-8}$ & $\mathrm{~m}^{3}$ \\
\hline Pipe area & $A_{\mathrm{p}}$ & $7.85 \times 10^{-5}$ & $\mathrm{~m}^{2}$ & Accumulator dead volume & $V_{\mathrm{agd}}$ & $1 \% \cdot V_{\mathrm{c}}$ & $\mathrm{m}^{3}$ \\
\hline Annular area of piston & $A_{\mathrm{rod}}$ & $1.26 \times 10^{-3}$ & $\mathrm{~m}^{2}$ & Initial volume of cap-end chamber & $V_{\mathrm{ic}}$ & $3.93 \times 10^{-4}$ & $\mathrm{~m}^{3}$ \\
\hline Discharge coefficient & $C_{\mathrm{d}}$ & 0.7 & - & Initial volume of rod-end chamber & $V_{\mathrm{rc}}$ & $6.38 \times 10^{-4}$ & $\mathrm{~m}^{3}$ \\
\hline
\end{tabular}

${ }^{*} V_{\mathrm{c}}$ is the accumulator capacity. $0.16 \mathrm{~L}, 0.32 \mathrm{~L}, 0.50 \mathrm{~L}$ and $0.75 \mathrm{~L}$ were used in this study.

The table also shows that there are, however, a number of system parameters whose values are uncertain hence they need to be estimated. As shown in Figure 4, such parameters and variables can be categorised in two: (1) Parameters related to power generation, including the voltage constant coefficient $k_{\mathrm{V}}$, the torque constant coefficient $k_{\mathrm{T}}$ and the rotational friction torque $T_{\mathrm{rf}}$; and (2) Variables associated with hydraulic flow which are the effective bulk modulus of the fluid $\beta$ (which will be different for the four locations $\beta_{\text {cap }}$ or $\beta_{\text {rod }}$ or $\beta_{\mathrm{m}}$ ), the mechanical efficiency $\eta_{\mathrm{m}}$ and the volumetric efficiency $\eta_{\mathrm{v}}$ of the hydraulic motor. The objective of this section is to obtain accurate parameters values for those parameters in the system which cannot be predetermined. A series of online tests were performed to estimate $k_{\mathrm{V}}, k_{\mathrm{T}}, R_{\mathrm{in}}$ and $T_{\mathrm{rf}}$ in the power regeneration unit. Furthermore, an offline test for the generator was designed to confirm the validity of $k_{\mathrm{V}}$ and $k_{\mathrm{T}}$. In addition, to determine more accurately the system behaviour and power output, fluid losses and friction were considered in modelling and thus $\eta_{\mathrm{m}}$ and $\eta_{\mathrm{v}}$ can be calculated for further improvement of the prototype system. From a fluid dynamics modelling standpoint, it is necessary to determine an appropriate bulk modulus model of the fluid that is in the hydraulic circuit; this is especially important for high pressure hydraulic systems.

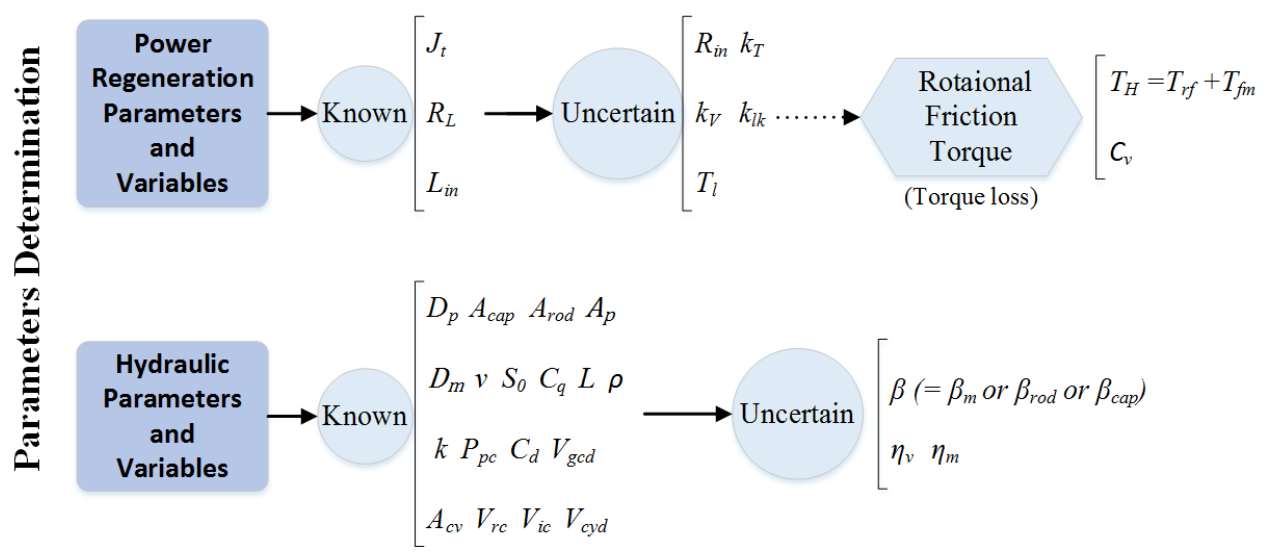

Figure 4. Known and uncertain parameters and variables in power regeneration unit and hydraulic system. 


\subsection{Power Regeneration System}

According to Equations (27)-(31), the performance of the equivalent DC generator to the rectified alternator used in the study is dependent upon the internal resistance $R_{\mathrm{in}}$, the voltage constant coefficient $k_{\mathrm{V}}$ and the torque constant coefficient $k_{\mathrm{T}}$. Based on an inverse estimation approach [38], these parameters were obtained with reference to online speed, current and voltage measurements under different external loads. Solving Equation (29) obtains the electrical current and then provides the voltage prediction $U_{\mathrm{pre}}\left(k_{\mathrm{V}, i}, R_{\mathrm{in}, j}\right)$ across the external resistances under a number of incremental voltage constants $k_{\mathrm{V}, i}$ and internal resistances $R_{\mathrm{in}, j}$. The minimum value of the least square error between the measured and the predicted voltage according to Equation (32) can then be derived as follows:

$$
\operatorname{error}\left(k_{\mathrm{V}}, R_{\mathrm{in}}\right)=\sum_{i=1}^{m} \sum_{j=1}^{n}\left\{U-U_{\mathrm{pre}}\left(k_{\mathrm{V}, i}, R_{\mathrm{in}, j}\right)\right\}^{2}
$$

where $U$ is the measured voltage, $U_{\text {pre }}$ represents the voltage prediction for the calculation of the electrical parameters study, $m$ and $n$ are the numbers of the search processes, and $i$ and $j$ define the search starting points.

Figure 5a shows the relationship between the voltage constant and the internal resistance obtained from measurements made directly on the test rig (referred to hereafter as online measurements), and using four different external resistances. Clearly the optimal internal resistance $R_{\text {in }}$ and the voltage constant coefficient $k_{\mathrm{V}}$ are clearly at the intersection point in Figure $5 \mathrm{a}$, is $k_{\mathrm{V}}=0.9256$ and $R_{\text {in }}=5.6 \Omega$.
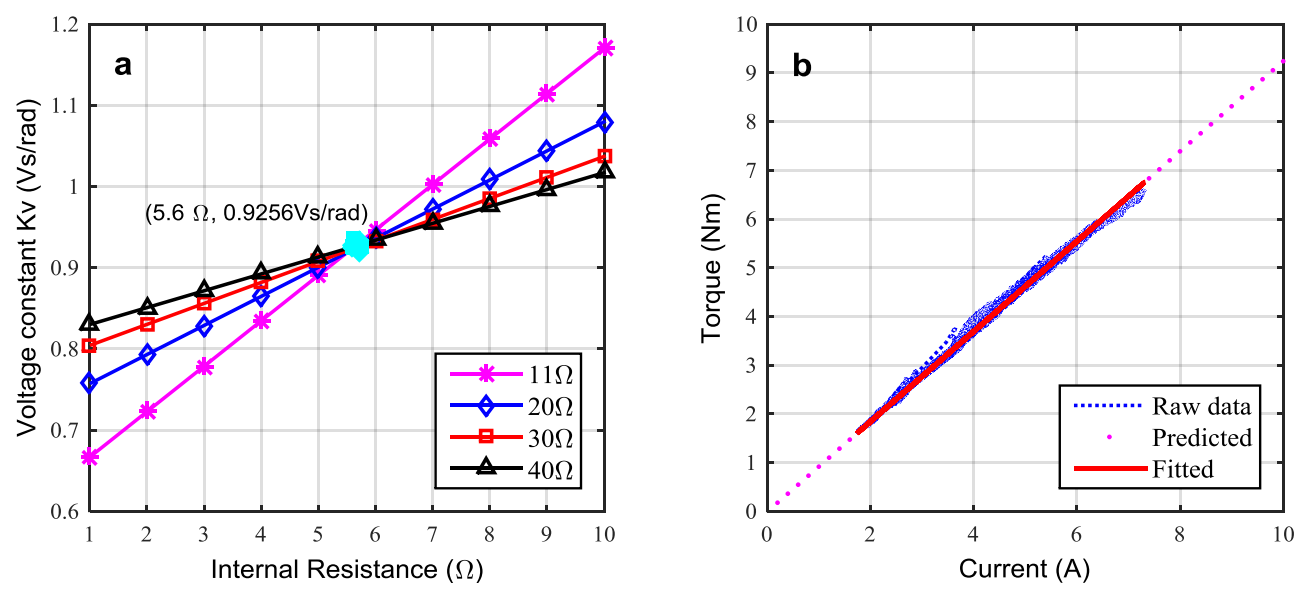

Figure 5. (a) Online voltage constant coefficient vs internal resistance; (b) online fitted torque constant coefficient, $k_{\mathrm{T}}$.

Figure $5 \mathrm{~b}$ shows the relationship between the effective motor torque and instantaneous current, the gradient of which is the torque constant $k_{\mathrm{T}}$. A parameter that plays an important role in the rotary motion of the motor and generator unit is the rotational friction torque $T_{\mathrm{rf}}$, and this was given priority in the estimation of $k_{\mathrm{T}}$. In Equation (25), it can be seen that $T_{\mathrm{rf}}$ is proportional to the viscous friction coefficient and the shaft speed. To obtain an accurate relationship between rotary motion and regenerative power, a set of online open circuit measurements were taken to find the viscous coefficient. In these measurements the flow energy or the motor torque $T_{\mathrm{m}}$ is just balanced by the frictional torque, considering low rate increase process the dynamic torque $J_{\mathrm{t}}\left(\mathrm{d} \omega_{\mathrm{m}} / \mathrm{d} t\right)$ can be ignored, which leads to the relationship of Equations (33)-(37):

$$
\begin{aligned}
& T_{\mathrm{m}}=\frac{D_{\mathrm{m}}\left(P_{\mathrm{m}}-P_{\text {loss }}\right) \eta_{\mathrm{m}}}{2 \pi}=T_{\mathrm{H}} \eta_{\mathrm{m}} \\
& =T_{\mathrm{H}}-\left(1-\eta_{\mathrm{m}}\right) T_{\mathrm{H}} \\
& =T_{\mathrm{H}}-T_{\mathrm{fm}}
\end{aligned}
$$


where $T_{\mathrm{H}}$ is the total output torque of the hydraulic motor and $T_{\mathrm{fm}}$ is the torque due to internal viscous drag of the hydraulic motor. It will be included into the total friction loss $T_{\mathrm{f}}$ of the system by redefining:

$$
T_{\mathrm{f}}=T_{\mathrm{rf}}+T_{\mathrm{fm}}=C_{\mathrm{v}} \omega_{\mathrm{m}}
$$

For the quasi static and open circuit experiments, and hence that Equation (26) can be reset to $\mathrm{d} \omega_{\mathrm{m}} / \mathrm{d} t \approx 0$ and $T_{1}=0$, the relationship of the torques can then be written as:

$$
\begin{gathered}
T_{\mathrm{m}}-T_{\mathrm{rf}}=0 \\
T_{\mathrm{H}}-T_{\mathrm{fm}}-T_{\mathrm{rf}}=0
\end{gathered}
$$

Both $T_{\mathrm{fm}}$ and $T_{\mathrm{rf}}$ are due to the friction, which is regarded as the effect of viscous loss:

$$
T_{\mathrm{H}}=T_{\mathrm{fm}}+T_{\mathrm{rf}}=\text { frictional torque }=C_{\mathrm{v}} \omega_{\mathrm{m}}
$$

Figure 6 shows the relationship between the motor torque $T_{\mathrm{m}}$, calculated by using Equation (24), with the pressure and the speed obtained through measurement. It can be seen that they are linearly correlated if the fluctuations due to the inertial torque are neglected. With the linear fit shown in Figure 6, the equivalent viscous friction coefficient $C_{\mathrm{v}}$ can be estimated to be 0.018 at the speed of motor in the range of 447-1698 rpm.

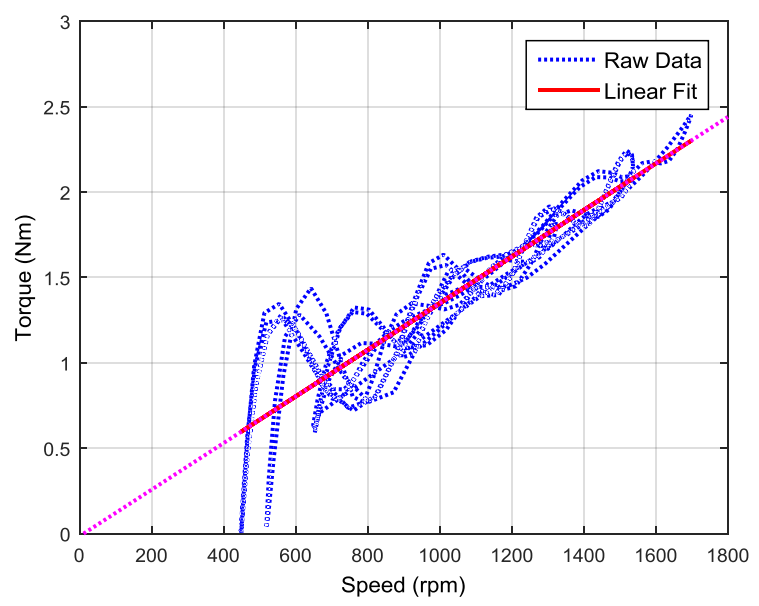

Figure 6. Fitted viscous friction torque based on online pressure and speed measurements.

In the equivalent DC generator, it was assumed that there are no electromagnetic losses from effects such as eddy currents, hysteresis and dielectric heating. Therefore, the effective mechanical power $\left(T_{\mathrm{m}}-T_{\mathrm{rf}}\right) \omega_{\mathrm{m}}$ is approximately equal to the electrical power which is produced by the EMF and the current of the generator armature. It can be found using in Equation (37), that theoretically at least, $k_{\mathrm{V}}$ is close in value to $k_{\mathrm{T}}$, and the slope of the curve of the torque constant coefficient can be found explicitly from Figure $5 \mathrm{~b}$ as being $k_{\mathrm{T}}=0.9246$.

$$
\frac{E I}{\omega_{\mathrm{m}}}=T_{\mathrm{m}}-T_{\mathrm{rf}}=k_{\mathrm{I}} I+J_{\mathrm{t}} \frac{\mathrm{d} \omega_{\mathrm{m}}}{\mathrm{d} t}
$$

The electrical parameters $\left(k_{\mathrm{V}}\right.$ and $k_{\mathrm{T}}$ ) have significant influence on the electrical efficiency and dynamic behaviour of the whole system and for this reason, an additional validation of the electrical parameters was performed using an offline test approach whereby the generator was coupled directly to an electric motor drive as shown in Figure 7. 


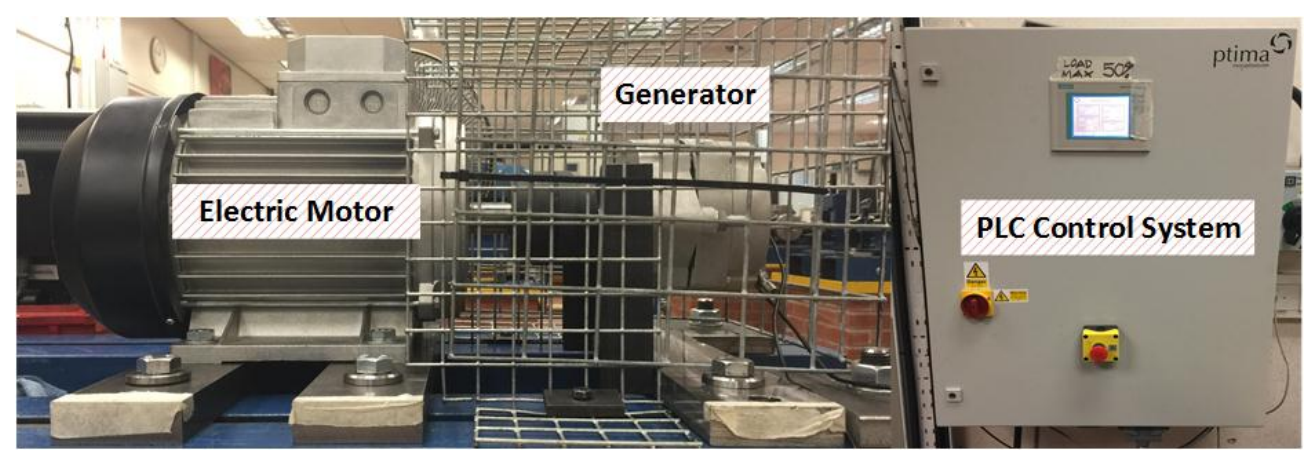

Figure 7. View of experimental generator test set up.

In the directly coupled offline test, an electrical load was set to values of $11,20,30$ and $40 \Omega$, and the mean voltage and current were measured at 150, 300, 450, 600, 750 and $900 \mathrm{rpm}$ for each value of resistance. The average torque was calculated by a programmable logic controller (PLC), and the results are shown in Figure 8a,b.
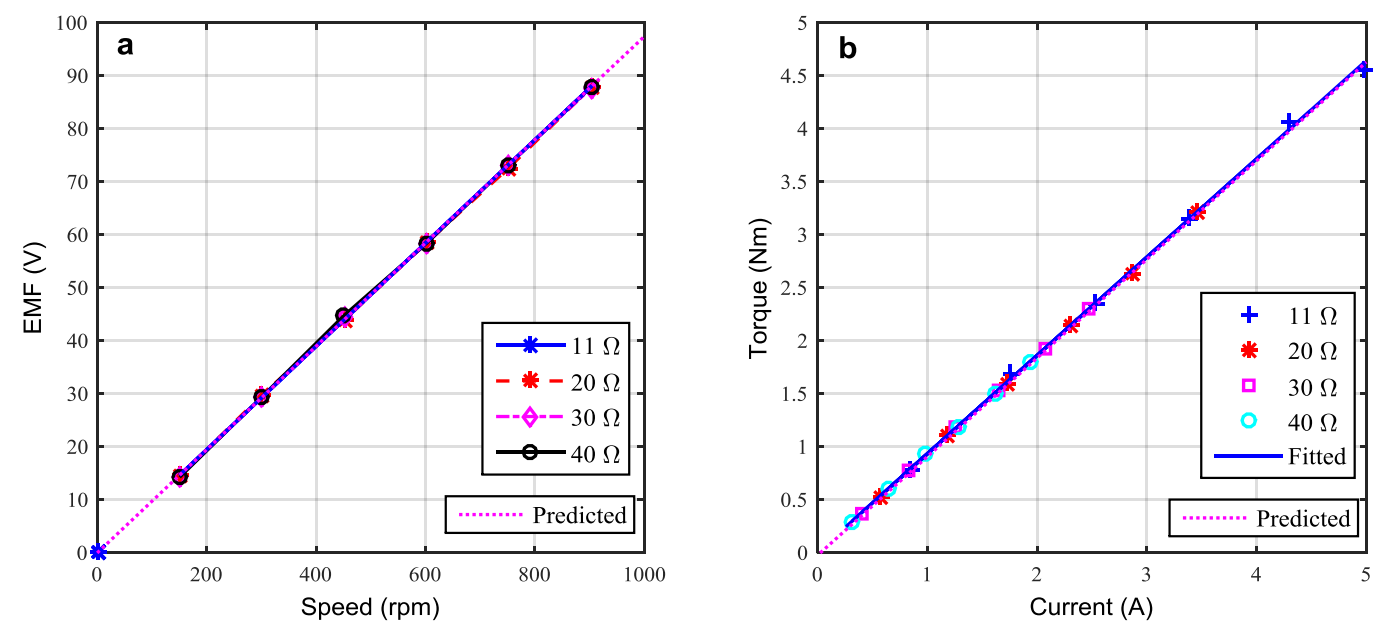

Figure 8. (a) Offline fitted voltage constant; (b) offline fitted torque constant.

The offline tests provided the following values for voltage constant coefficient and torque constant coefficient, $k_{\mathrm{V}}=0.9303$ and $k_{\mathrm{T}}=0.9274$, these compare to online estimations of $k_{\mathrm{V}}=0.9256$ and $k_{\mathrm{T}}=0.9246$, showing that there is close agreement between the estimation approaches and also that $k_{\mathrm{V}}$ and $k_{\mathrm{T}}$ are very similar in value.

\subsection{Hydraulic System}

In this study, the mechanical and volumetric efficiencies in the hydraulic motor and the effective bulk modulus of the hydraulic fluid, were determined by modelling of the hydraulic system. In modelling, the assumptions made during this process were as follows:

- Firstly, the hydraulic cylinder was assumed to be frictionless and without leakage.

- Secondly, in Equation (20), the mean values of the time-varying pressure and speed of the motor were taken as the nominal pressure drop (for the calculation of the hydraulic motor leakage coefficient) and the nominal shaft speed, respectively.

- Thirdly, the values of $k_{\mathrm{T}}$ and $k_{\mathrm{V}}$ were used as determined in Section 4.1, meaning that there are no additional electrical losses in the generator model to be accounted for, hence it can be assumed that the hydraulic motor power output $P_{\mathrm{m}}$ is equal to the power captured in the generator $P_{\text {cap. }}$. 
Mechanical and volumetric losses are the main influences on the hydraulic motor's efficiency. Based on the above-mentioned assumptions, the mechanical efficiency $\eta_{\mathrm{m}}$ can be expressed as:

$$
\eta_{\mathrm{m}}=\frac{D_{\mathrm{m}}\left(P_{\mathrm{m}}-P_{\text {loss }}\right)-2 \pi T_{\mathrm{rf}}}{D_{\mathrm{m}}\left(P_{\mathrm{m}}-P_{\text {loss }}\right)}
$$

The ratio of the $P_{\text {cap }}$ to the initial input power $P_{\text {in }}$ is defined as generator captured efficiency $\eta_{\text {cap }}$ and expressed by Equation (41). The volumetric efficiency $\eta_{v}$ of the motor was calculated using the captured power efficiency $\eta_{\text {cap }}$ in the generator and the mechanical efficiency $\eta_{\mathrm{m}}$ in the hydraulic motor. Therefore, the $\eta_{\mathrm{v}}$ can be defined as:

$$
\begin{gathered}
P_{\text {cap }}=I^{2}\left(R_{\text {in }}+R_{\mathrm{L}}\right) \\
\eta_{\text {cap }}=\frac{P_{\text {cap }}}{P_{\text {in }}} \\
\eta_{\mathrm{v}}=\frac{\eta_{\text {cap }}}{\eta_{\mathrm{m}}}
\end{gathered}
$$

The effective bulk modulus of the fluid is representative of its compressibility and is the gauge of stiffness within the hydraulic system; this will vary with temperature and the amount of entrained air. In any hydraulic system, hydraulic fluid is always accompanied by a small amount of non-dissolved and entrained gas, which can be quantified by the gas ratio $\alpha$. Any entrained air will cause air bubbles that will significantly reduce the bulk modulus value and hence adversely affect the power regeneration capability. The effective bulk modulus was estimated to vary nonlinearly with pressure, as shown in Figure 9, and as described below.
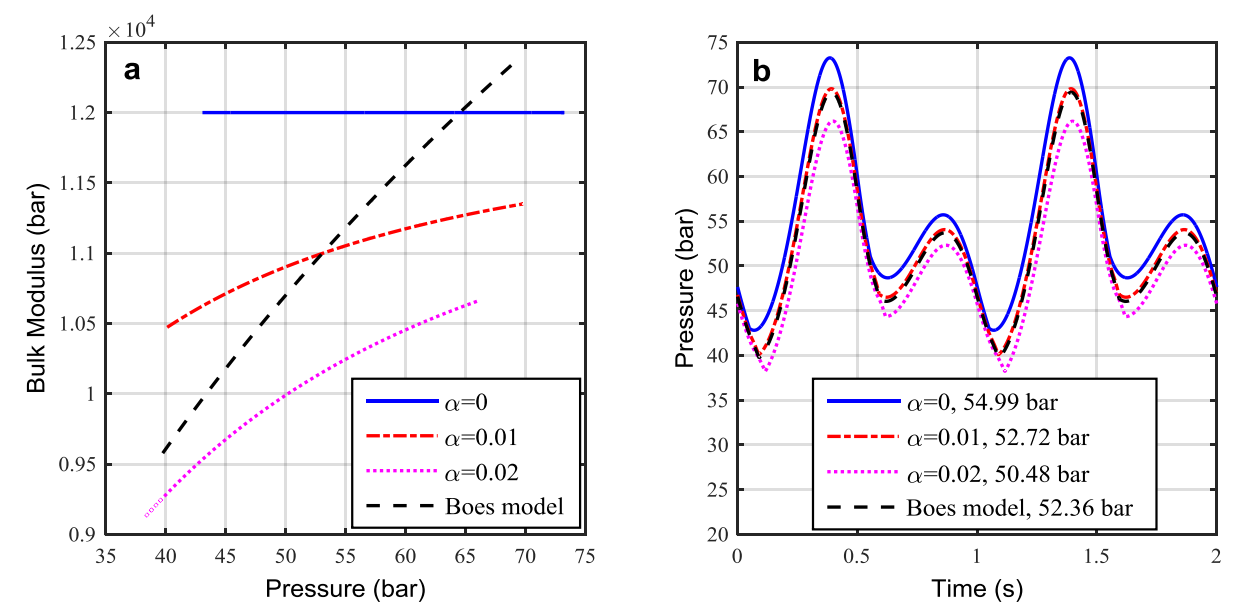

Figure 9. (a) Bulk modulus variation with motor pressure; (b) predicted motor pressures for different bulk modulus values.

The effects of entrained air and mechanical compliance can be determined from direct measurements then using fundamental effects, the entrained air as proposed by Backe and Murrenhoff [39] in the following formulae for the isentropic bulk modulus of liquid-air mixtures (air ratio $\alpha$ ), can be calculated as follows:

$$
\beta_{\mathrm{e}}=\beta_{\text {ref }} \frac{1+\alpha\left(\frac{P_{\mathrm{a}}}{P_{\mathrm{a}}+P}\right)}{1+\alpha \frac{P_{\mathrm{a}}^{1 / k}}{n \cdot\left(P_{\mathrm{a}}+P\right)^{\frac{k+1}{k}}} \beta_{\text {ref }}}
$$


where $P_{\mathrm{a}}$ is the atmospheric pressure, $n$ is the gas specific heat ratio, and $P$ is the relevant pressure $\left(P_{\text {cap }}, P_{\text {rod }}\right.$ or $\left.P_{\mathrm{m}}\right)$.

Generally, there are a several empirical determinations for effective bulk modulus. Boes's model [40] is the one of the more commonly used for a hydraulic cylinder based system, and has been used in this study because of its simplicity and specific application to low pressure systems (under 100 bar). In accordance with the guidelines for hydraulic system modelling from the Institute for Fluid Power Drives and Controls, Rheinisch-Westfälische Technische Hochschule (RWTH) Aachen, Germany [39,40], the application specific parameter values of 0.5, 99 and 1 in Equation (44) were selected because the system in a low pressure system [40].

The Boes' Model used is hence:

$$
\beta_{\mathrm{e}}=0.5 \cdot \beta_{\text {ref }} \cdot \log \left(99 \frac{P}{P_{\text {ref }}}+1\right)
$$

In the Boes' model, the reference bulk modulus $\beta_{\text {ref }}$ and the reference pressure $P_{\text {ref }}$ are constants and the values used are $1.2 \times 10^{9} \mathrm{~Pa}$ and $1 \times 10^{7} \mathrm{~Pa}$ respectively, again selected using the guideline in [40]. To calculate the effective bulk modulus, the gas ratio $\alpha$ was set to values of $0,0.01$, and 0.02 which are typical of a hydraulic cylinder [39]. For the same operating conditions, the smaller the predefined air ratio, the larger the motor pressure due to the reduced compressibility of the fluid. In real applications, it can be difficult to define a proper air ratio due to the variable solubility of the gas, which is dependent on both temperature and working pressure, and in Figure 9, the Boes' bulk modulus shows a large variation from 9860 bar to 12,450 bar. The expressions for the determined effective bulk modulus are values shown in Equations (45)-(47):

$$
\begin{gathered}
\beta_{\text {cap }}=0.5 \cdot \beta_{\text {ref }} \cdot \log \left(99 \cdot \frac{P_{\text {cap }}}{P_{\text {ref }}}+1\right)(\text { Cap }- \text { endchamber }) \\
\beta_{\text {rod }}=0.5 \cdot \beta_{\text {ref }} \cdot \log \left(99 \cdot \frac{P_{\text {rod }}}{P_{\text {ref }}}+1\right)(\text { Rod-endchamber }) \\
\beta_{\mathrm{m}}=0.5 \cdot \beta_{\text {ref }} \cdot \log \left(99 \cdot \frac{P_{\mathrm{m}}}{P_{\text {ref }}}+1\right)(\text { Hydraulicdmotorchamber })
\end{gathered}
$$

At this point, all of the parameter originally identified in Figure 4 as "To Be Determined" can now be quantified, and expressions have been determined for all of the variables as follows in Figure 10:

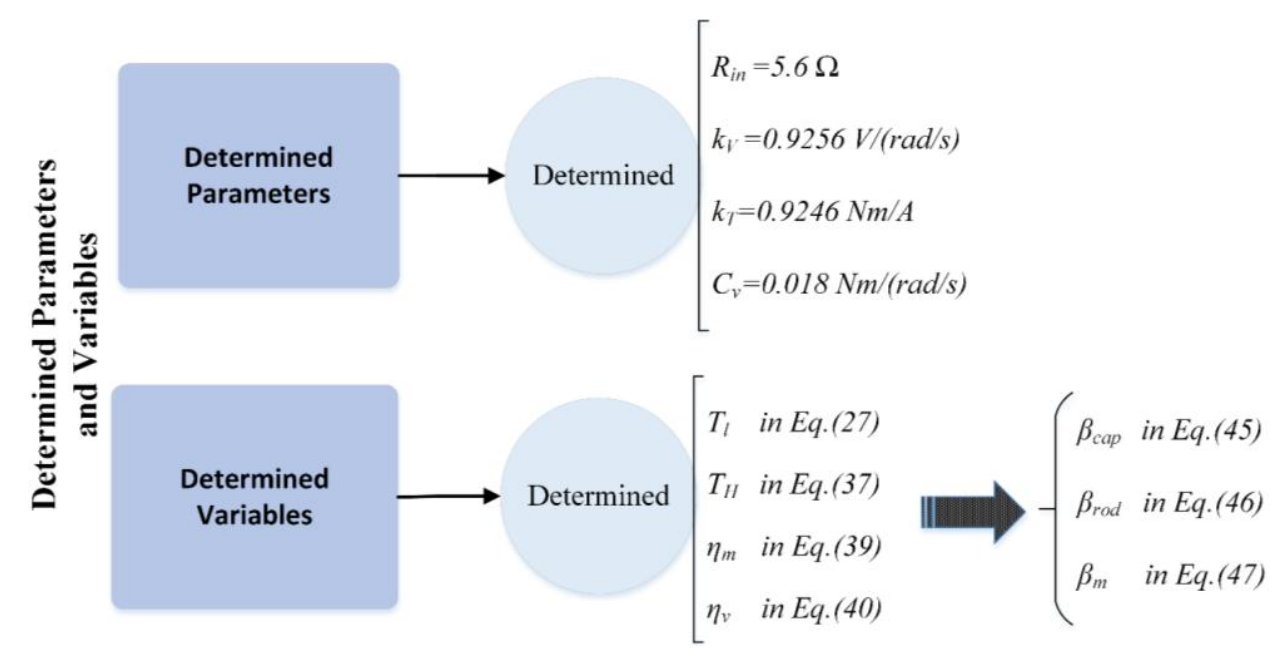

Figure 10. Determined parameters and variables in power regeneration unit and hydraulic system. 


\section{Results and Discussion}

To validate the model predicted behaviour, the test facility described in Section 3.5 was used under different excitations and load resistances. In addition, the effects of the accumulator capacity were also considered. In both modelling and testing, the predefined excitations are consistent with the open circuit measurements for the estimation of the viscous friction coefficient in Section 4.1.

\subsection{Validation Using Excitations}

Clearly, the main source of vibration of a vehicle is the excitation input from the road surface. For this reason the first model validation applied different excitations of $0.5 \mathrm{~Hz}, 25 \mathrm{~mm}$ and $1 \mathrm{~Hz}$, $20 \mathrm{~mm}$, both using an accumulator volume of $0.16 \mathrm{~L}$ and a load resistance of $11 \Omega$. The performance study focused on the variations between the motor pressure drop and the rotational motion. Using the refined parameters of the proposed system obtained from the parameter identification study of Section 4, close agreement between the measured and predicted results was obtained. The hydraulic motor inlet pressure and the shaft speed differences between prediction and measurement are shown in Figures 11 and 12. It can be seen that higher excitation causes greater pressure, hence results in higher motor speed.
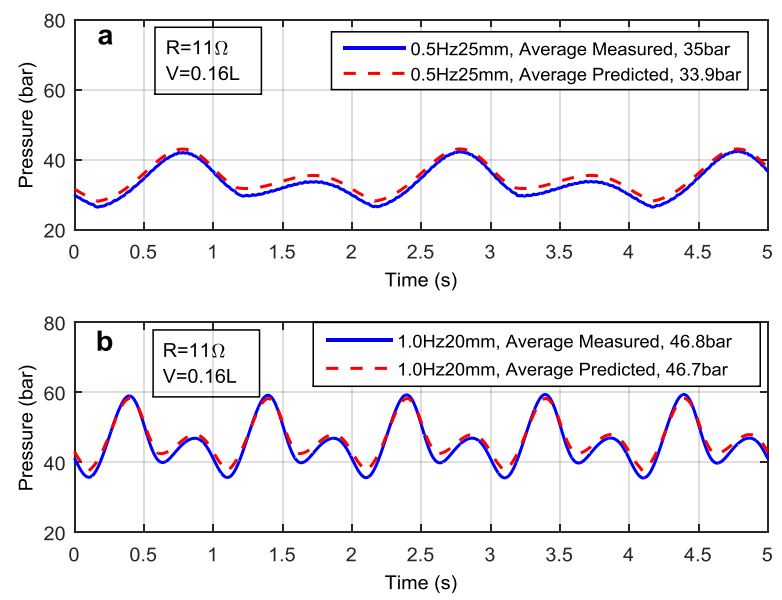

Figure 11. Predicted and measured pressure at (a) $0.5 \mathrm{~Hz}$ frequency and $25 \mathrm{~mm}$ amplitude; and (b) $1.0 \mathrm{~Hz}$ frequency and $20 \mathrm{~mm}$ amplitude ( $R$ is equal to the external load $R_{\mathrm{L}}$ and $V$ is the same as accumulator capacity $V_{\mathrm{c}}$ ).
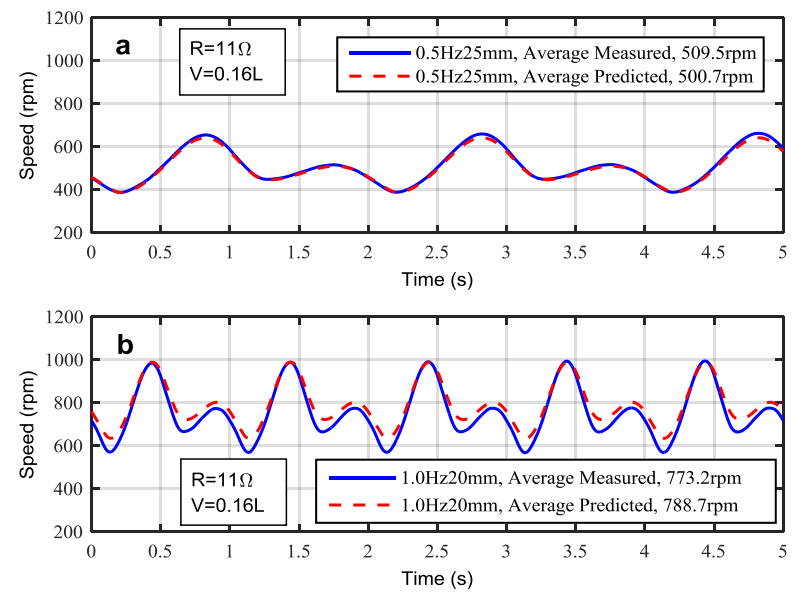

Figure 12. Predicted and measured motor speed at (a) $0.5 \mathrm{~Hz}$ frequency and $25 \mathrm{~mm}$ amplitude; and (b) $1.0 \mathrm{~Hz}$ frequency and $20 \mathrm{~mm}$ amplitude. 


\subsection{Validation Using Different Load Resistances}

To explore the power regeneration capability and in the process to validate the proposed model, different load resistances were applied. It is clear that the predicted and measured power can be seen to gradually decrease with an increase in load resistance, as shown in Figure 13.
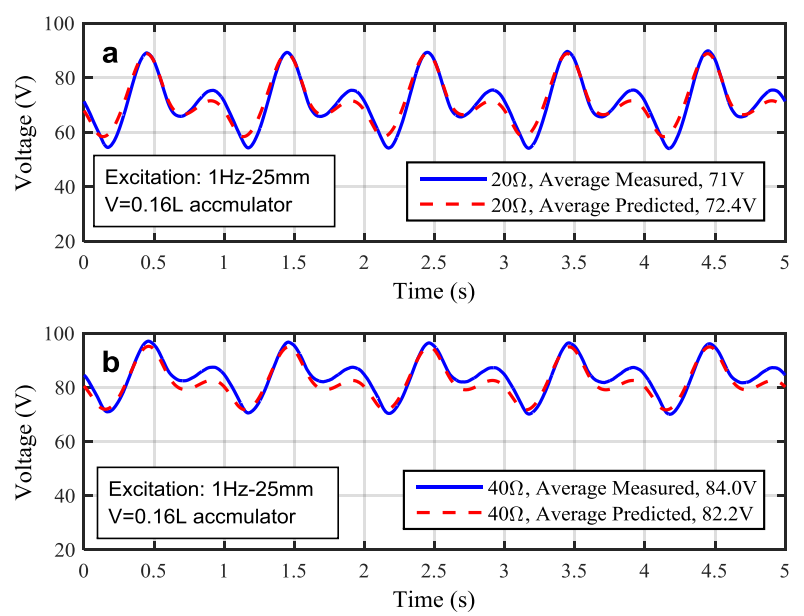

Figure 13. Predicted and measured voltage at (a) $20 \Omega$ load resistance; and (b) $40 \Omega$ load resistance.

Further increase in resistance results in a relatively small amount of regenerated power [23]. In Figures 13 and 14 the output voltage and power are in good agreement between prediction and measurement. However, the load resistance of $20 \Omega$ provides the best efficiency (39.74\%) with an average power recovery of $258.1 \mathrm{~W}$ compared to $34.2 \%$ and $168.3 \mathrm{~W}$ at $40 \Omega$. The measured displacement-force loops and velocity-force loops under the different load conditions are shown in Figure 15. It is clear that a wide range of different damping forces can be obtained by adjusting the load resistance, which can be further optimised for a semi-active regenerative shock absorber in heavy haulage vehicles.
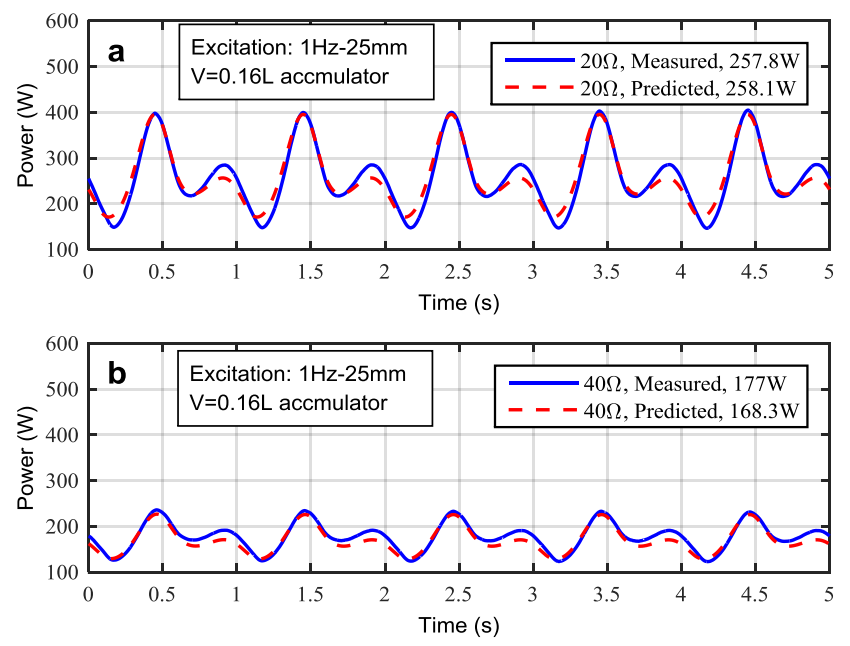

Figure 14. Predicted and measured power at (a) $20 \Omega$ load resistance; (b) $40 \Omega$ load resistance. 

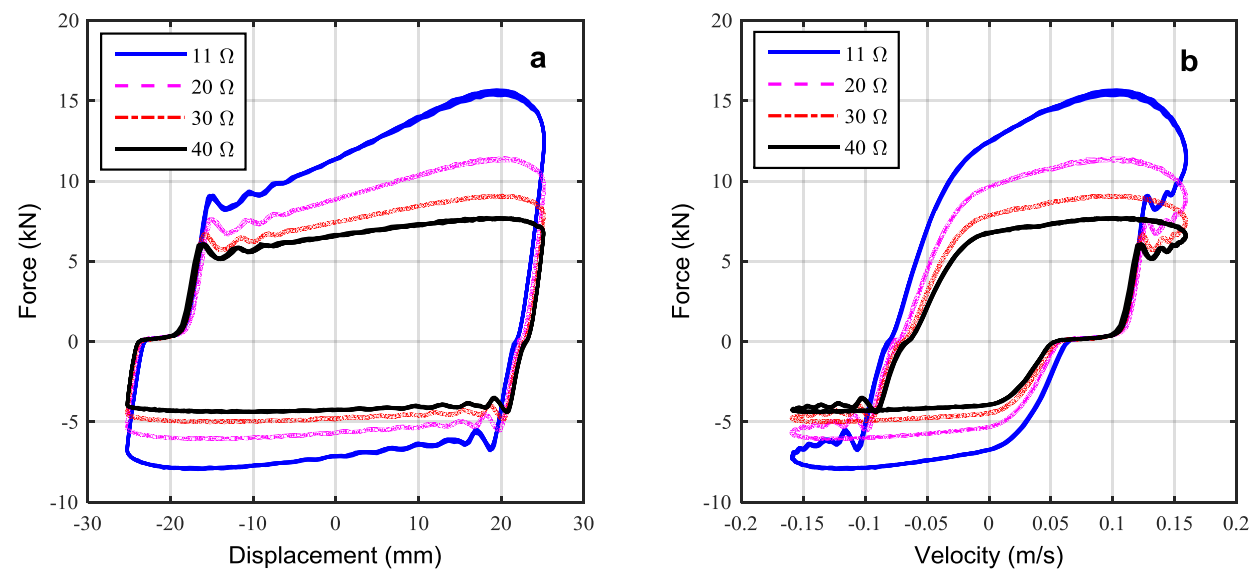

Figure 15. (a) Measured displacement-force loops; (b) measured velocity-force loops, at $11 \Omega, 20 \Omega$, $30 \Omega$ and $40 \Omega$ load resistances.

\subsection{The effect of Accumulator Capacity}

Testing under $1 \mathrm{~Hz}$ frequency and $25 \mathrm{~mm}$ amplitude excitation, with an optimal load resistance of $20 \Omega$, was then evaluated at different accumulator capacities and the predicted and measured results are displayed in Figures 16 and 17. The motor pressure and regenerated power shows close correlation between measurement and prediction. However, there is a slightly greater inconsistency between the predicted and the measured shaft speeds. With increasing accumulator capacities, the peak values of the shaft speed corresponding to the cap-end pressure decreased, representing an inverse variation with those in the modelling, this effect increases with accumulator capacity.
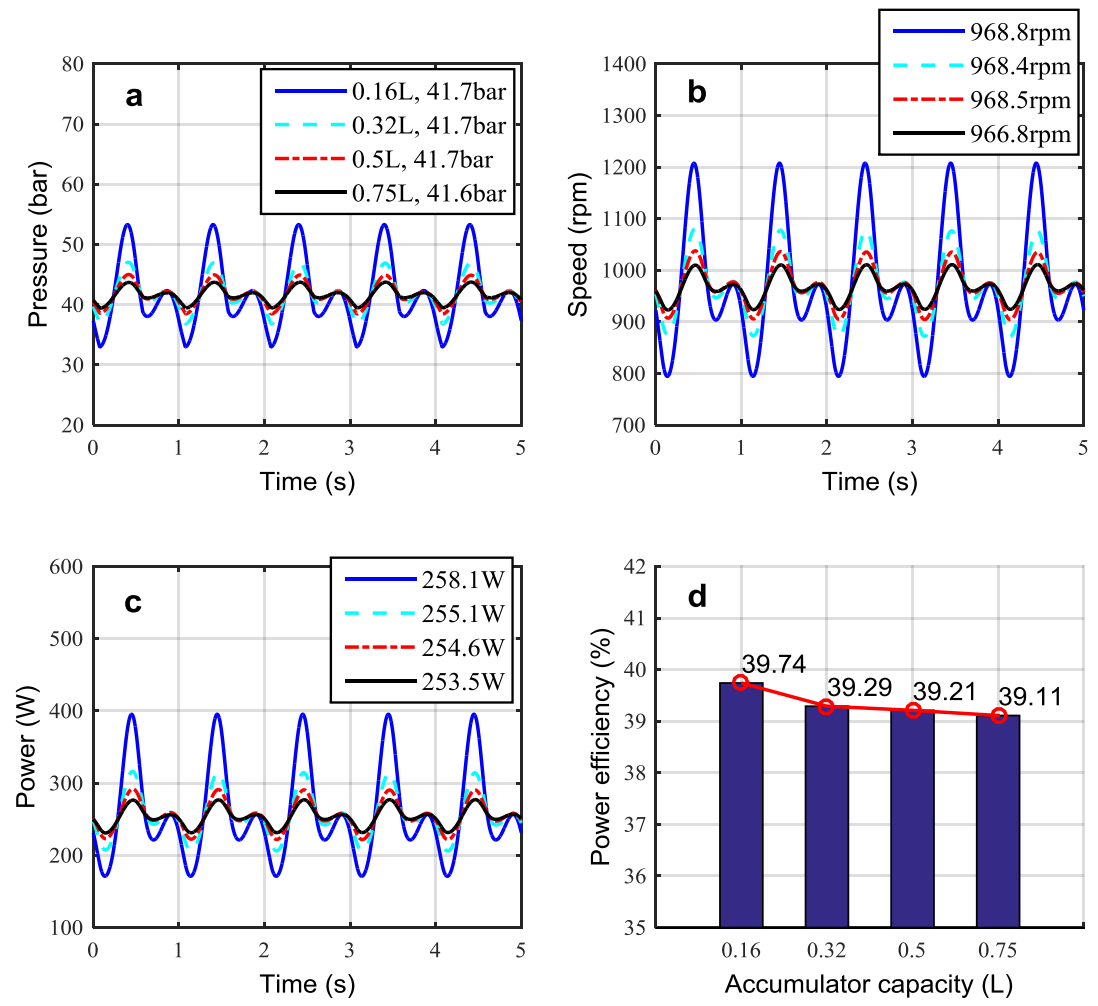

Figure 16. (a) Predicted motor pressure; (b) predicted shaft speed; (c) predicted regenerative power; (d) predicted power regeneration efficiency, at $0.16 \mathrm{~L}, 0.32 \mathrm{~L}, 0.50 \mathrm{~L}$ and $0.75 \mathrm{~L}$ accumulator capacities. 

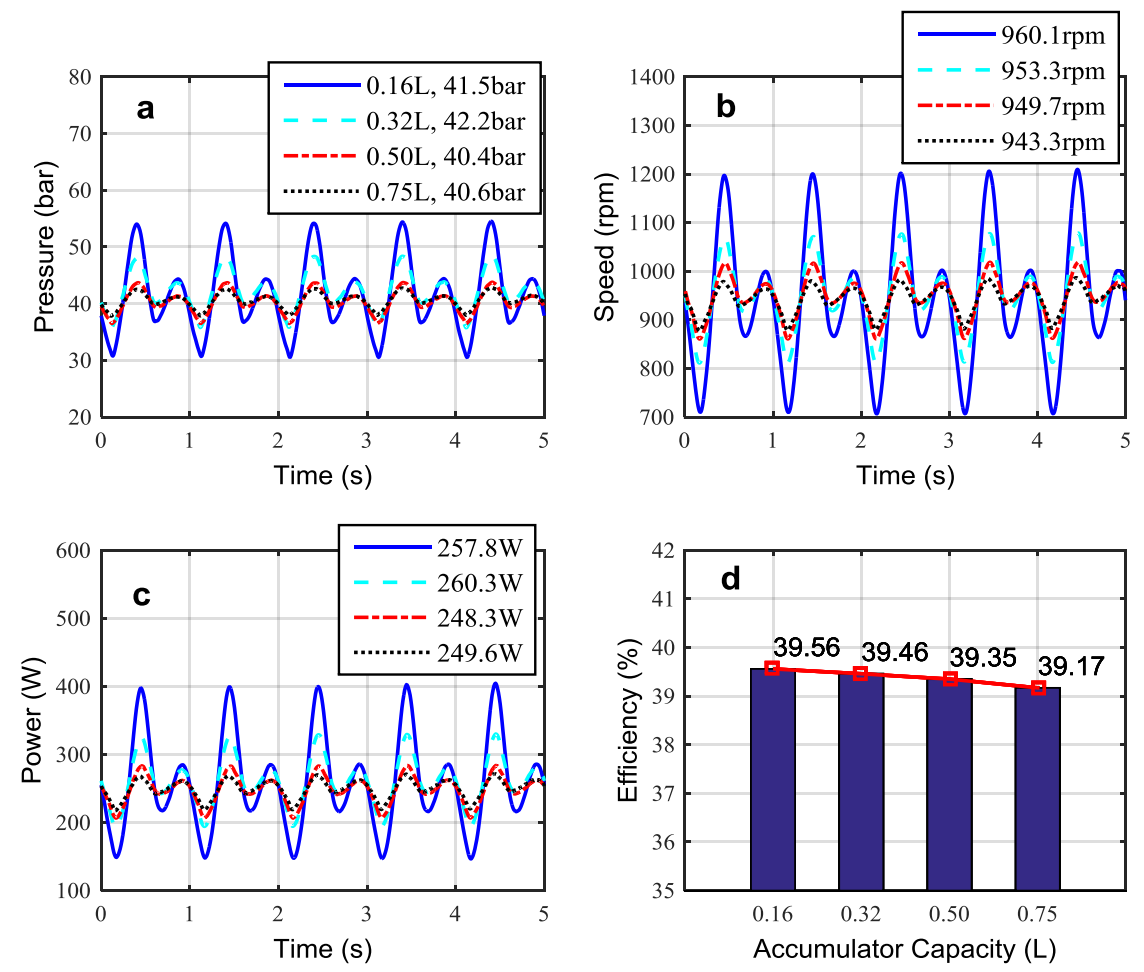

Figure 17. (a) Measured motor pressure; (b) measured shaft speed; (c) measured regenerative power; (d) measured power regeneration efficiency, at $0.16 \mathrm{~L}, 0.32 \mathrm{~L}, 0.50 \mathrm{~L}$ and $0.75 \mathrm{~L}$ accumulator capacity.

The motor outlet pressure in the test system was not uniform although it had been set as a constant in the model, and the effective pressure drop in the motor chamber was smaller than that used in modelling. In Figures $16 \mathrm{~b}$ and $17 \mathrm{~b}$, it can be seen that the average and peak values of the shaft speed are smaller than those used in modelling. In addition, the deflection of the test rig frame leads to an inevitable small misalignment between the motor and generator shaft, which in turn reduces the effective motor torque and shaft speed.

The inherent characteristics of a diaphragm accumulator are such that it can prevent fluid shocks from highly oscillating flows and also balance pulsations of the fluid with only a small amount of the pressure consumption. The accumulator is therefore able to operate as a pressure compensation element or energy storage device in a low pressure process to provide the continuity and stability of the pressurised flow. Figures 16a and 17a show that the mean pressure after the accumulator port (which is upstream of the motor inlet) is around $41 \mathrm{bar}$, and the power outputs and the regeneration efficiency are approximately $260 \mathrm{~W}$ and $40 \%$, respectively. It can also be seen from Figures 16 and 17 that increase in accumulator capacity from $0.16 \mathrm{~L}$ to $0.75 \mathrm{~L}$ can improve the stability of the entire system without significantly influencing the average motor inlet pressure, shaft speed or power.

Additionally, based on the experimental work, the volumetric efficiency of the hydraulic motor can be obtained by using the ratio of actual fluid flow out of the hydraulic motor to total theoretical fluid flow out of the shock absorber chambers. Therefore, the calculation process is given and shown in Figure 18. It assumes that the total fluid flow $Q_{T}$ is equal to the theoretical flows from the shock absorber body $\left(Q_{\text {cap,m }}\right.$ and $\left.Q_{\text {rod,m }}\right)$ which is actuated by the excitation input $v(t)$. The hydraulic motor flow can be calculated by using the displacement of the motor and measured motor speeds, then the average volumetric efficiency can also be estimated for measured results. The measured volumetric efficiency therefore can be provided to validate against the predictions. However, Figure 19 shows that the predicted and measured volumetric efficiency are in good agreement. It also indicates that the effect of accumulator capacity can efficiently stabilise the system behaviours with acceptable recoverable power, and also the volumetric efficiency and the regeneration efficiency are changed very slightly. 


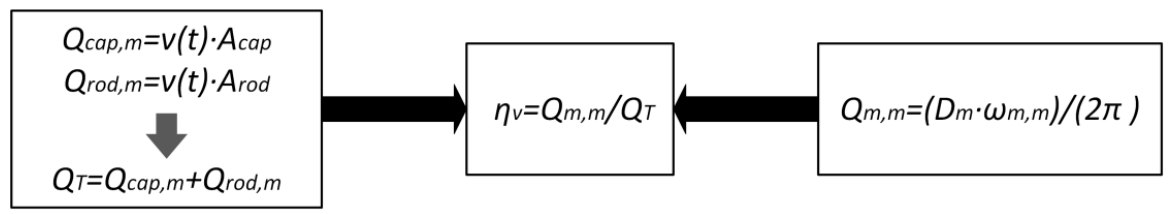

Figure 18. The calculation process of the measured volumetric efficiency.

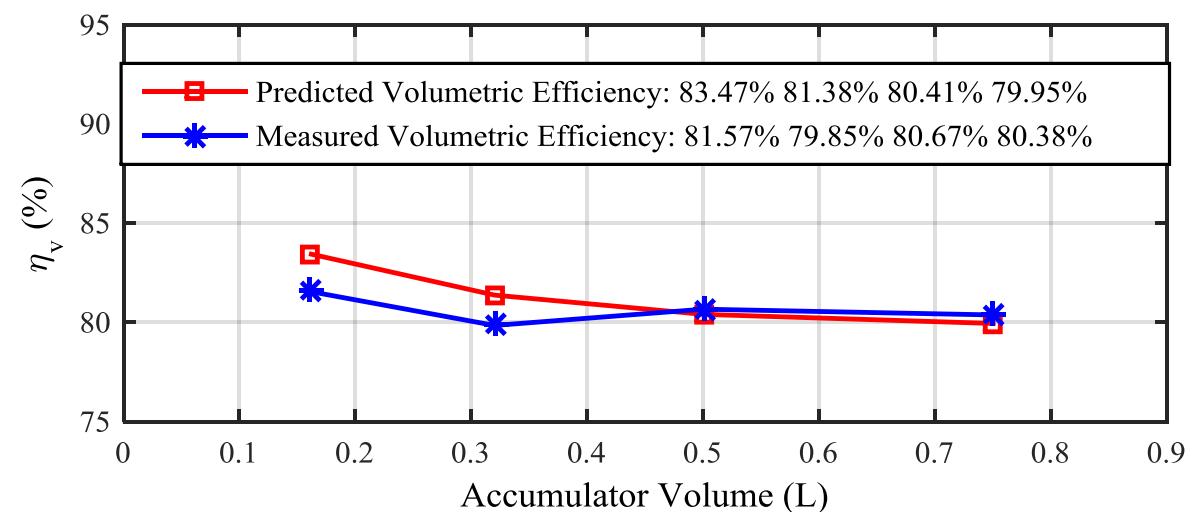

Figure 19. Hydraulic motor volumetric efficiency between predictions and measurements at $0.16 \mathrm{~L}$, $0.32 \mathrm{~L}, 0.50 \mathrm{~L}$ and $0.75 \mathrm{~L}$ accumulator capacities.

In the measured displacement-force loops and velocity-force loops, which are shown in Figure 20, it can be seen that the forces on the piston (equivalent to damping forces) are further stabilised and regulated during the compression stroke by increasing the accumulator capacity and that the peaks decrease from $11.46 \mathrm{kN}$ to $9.33 \mathrm{kN}$ (close to a $20 \%$ reduction). The peak values of the damping forces at $0.5 \mathrm{~L}$ and $0.75 \mathrm{~L}$ accumulator volumes are similar in the compression and extension strokes because these are appropriate accumulator capacities for the magnitude of excitation.
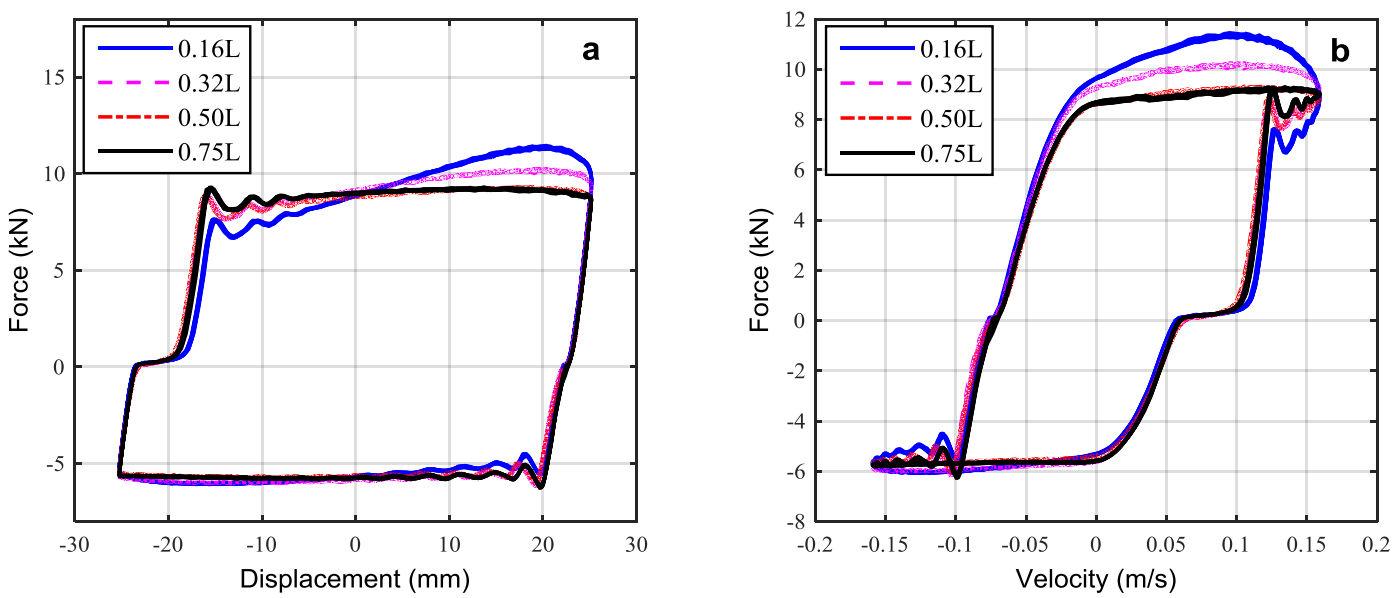

Figure 20. (a) Measured displacement-force loops; (b) measured velocity-force loops, at $0.16 \mathrm{~L}, 0.32 \mathrm{~L}$, $0.50 \mathrm{~L}$ and $0.75 \mathrm{~L}$ accumulator capacities.

Based on the displacement-force loops and velocity-force loops shown in Figures 15 and 20 it can be seen that appropriately selected load resistance and accumulator capacity are able to provide adaptive damping characteristics that are suitable for use in a heavy haulage vehicle. However, the effects of the load resistance and accumulate capacity reveal that the regenerative shock absorber can allow acceptable damping force to the conventional hydraulic shock absorber which are comparable 
to the results for the heavy-duty trucks or buses in [36]. The study of accumulator capacity shows that adjusting accumulator capacities is a feasible method of achieving more recoverable power and adjusting to the damping forces during the compression and extension strokes of a hydraulic shock absorber.

\section{Conclusions}

This paper presents the design, modelling and analysis of the regenerative hydraulic shock absorber system in sinusoidal waves. An accurate model has been proposed, which considered the variations in valve flows and fluid bulk modulus, motor efficiencies, accumulator smoothing and inevitable system losses, and hence is helpful to fully understand the system behaviours and the capability of the power regeneration in common used regular waves prior to evaluating the system under various road surface profiles or road tests.

The uncertain parameters and variables of the hydraulic system and power regeneration unit have been determined. Both the online and offline determination approaches are sufficient to characterise the electrical parameters in the generator, ensure the maximum power regeneration and the accurate system behaviours. The determined rotational friction torque loss shows that it is conducive to finding the mechanical efficiency of the hydraulic motor in the modelling and the volumetric efficiency can be found to vary with the ratio between captured power and initial power input afterwards. Accurate predictive performances have been validated by measurements. The validation has not only been performed for the variations in motor pressure and shaft speed under different excitations, but also voltage output and recoverable power under load resistances and they have been shown to give good agreement between prediction and measurement. These results show that the excitation has a direct effect on the waveform of the hydraulic motor pressure and shaft speed. In the meantime, it reveals that the load resistance can be adjusted to give an optimum match both in values of the damping force and recoverable power.

The influence of the accumulator in a regenerative hydraulic shock absorber system has also been evaluated and shown to be a means by which the hydraulic behaviour and recoverable power can be optimised. It has been shown that the damping characteristics of a shock absorber can be adjusted by varying the load resistance and accumulator capacity. The power output of the developed facility was approximately 260 Watts with the power efficiency of $40 \%$, making it a realistic probability for the application in a typical heavy goods vehicle.

However, the predicted and measured results clearly and consistently show that load resistance directly impacts on hydraulic behaviour, rotary motion and power regeneration. The different accumulator capacities were shown to reduce pressure pulsation and make the entire regenerative shock absorber system stable.

Acknowledgments: The authors would like to thank the Centre for Efficiency and Performance Engineering in University of Huddersfield for the technical and financial supports and the staffs in Automotive Laboratory for equipment support.

Author Contributions: Ruichen Wang and Fengshou Gu contributed significantly to the modelling, testing and data analysis. Robert Cattley contributed to the manuscript preparation. Andrew Ball contributed to the correct errors in language and technique.

Conflicts of Interest: The authors declare no conflict of interest.

\section{References}

1. Khan, S.; Stadnyk, S.; Wilkes, E. Official Statistic: Energy Consumption in the UK; Department of Energy \& Climate Change: London, UK, 2013.

2. Zhang, P.-S. Design of Electromagnetic Shock Absorbers for Energy Harvesting from Vehicle Suspensions. Master's Thesis, Stony Brook University, Stony Brook, NY, USA, 2010.

3. Karnopp, D. Power requirements for vehicle suspension systems. Veh. Syst. Dyn. 1992, 21, 65-71. [CrossRef] 
4. Velinsky, S.A.; White, R.A. Vehicle energy dissipation due to road roughness. Veh. Syst. Dyn. 1980, 9, 359-384. [CrossRef]

5. Segel, L.; Lu, X. Vehicular resistance to motion as influenced by road roughness and highway alignment. Aust. Road Res. 1982, 12, 211-222.

6. Hsu, P. Power recovery property of electrical active suspension systems. In Proceedings of the 1996 31st Intersociety Energy Conversion Engineering Conference, Washington, DC, USA, 11-16 August 1996; Volume 3, pp. 1899-1904.

7. Zuo, L.; Zhang, P.-S. Energy harvesting, ride comfort, and road handling of regenerative vehicle suspensions. J. Vib. Acoust. 2013, 135. [CrossRef]

8. Zyga, L. Energy harvesting shock absorber technology wins R\&D 100 award. Phys. Org. 2011. Available online: http:/ / phys.org/news/2011-07-energy-harvesting-absorber-fuel-efficiency-award.html (accessed on 4 May 2016).

9. Li, Z.; Brindak, Z.; Zuo, L. Modeling of an Electromagnetic Vibration Energy Harvester with Motion Magnification. In Proceedings of the ASME 2011 International Mechanical Engineering Congress and Exposition, Denver, CO, USA, 11-17 November 2011; pp. 285-293.

10. Kavalchuk, I.; Arisoy, H.; Stojcevski, A.; Than Oo, M.T. Advanced simulation of power consumption of electric vehicles. Electr. Comput. Energ. Electron. Commun. Eng. 2015, 9, 53-59.

11. Suda, Y.; Nakadai, S.; Nakano, K. Study on the self-powered active vibration control. In Proceedings of the 4th International Conference on Motion and Vibration Control, Zürich, Switzerland, 25-28 August 1998.

12. Nakano, K.; Suda, Y.; Nakadai, S. Self-powered active vibration control using continuous control input. JSME Int. J. Ser. C 2000, 43, 726-731. [CrossRef]

13. Arsem, H.B. Electric Shock Absorber. U.S. Patent US3559027 A, 26 January 1971.

14. Suda, Y.; Shiiba, T.; Hio, K.; Kawamoto, Y.; Kondo, T.; Yamagata, H. Study on electromagnetic damper for automobiles with nonlinear damping force characteristics: (Road test and theoretical analysis). In Proceedings of the International Association for Vehicle System Dynamics Symposium, Kanagawa, Japan, 24-30 August 2003; Volume 41, pp. 637-646.

15. Li, Z.; Zuo, L.; Luhrs, G.; Lin, L.; Qin, Y.X. Electromagnetic energy-harvesting shock absorbers: Design, Modeling, and Road Tests. IEEE Trans. Veh. Technol. 2013, 62, 1065-1074. [CrossRef]

16. Sabzehgar, R.; Maravandi, A.; Moallem, M. Energy Regenerative Suspension Using an Algebraic Screw Linkage Mechanism. IEEE/ASME Trans. Mechatron. 2014, 19, 1251-1259. [CrossRef]

17. Avadhany, S.; Abel, P.; Tarasov, V.; Anderson, Z. Regenerative Shock Absorber. U.S. Patent US20090260935 A1, 22 October 2009.

18. Anderson, Z.; Jackowski, Z.; Bavetta, R. Regenerative Shock Absorber System. U.S. Patent US20100072760 A1, 25 March 2010.

19. Fang, Z.; Guo, X.; Xu, L.; Zhang, H. Experimental study of damping and energy regeneration characteristics of a hydraulic electromagnetic shock absorber. Adv. Mech. Eng. 2013, 5. [CrossRef]

20. Fang, Z.; Guo, X.X.; Xu, L.; Zhang, H. An optimal algorithm for energy recovery of hydraulic electromagnetic energy-regenerative shock absorber. Appl. Math. Inf. Sci. 2013, 7, 2207-2214. [CrossRef]

21. Li, C.P.; Tse, W. Fabrication and testing of an energy-harvesting hydraulic damper. Smart Mater. Struct. 2013, 22. [CrossRef]

22. Li, C.; Zhu, R.; Liang, M.; Yang, S. Integration of shock absorption and energy harvesting using a hydraulic rectifier. J. Sound Vib. 2014, 333, 3904-3916. [CrossRef]

23. Zhang, Y.; Zhang, X.; Zhan, M.; Guo, K.; Zhao, F.; Liu, Z. Study on a novel hydraulic pumping regenerative suspension for vehicles. J. Frankl. Inst. 2015, 352, 485-499. [CrossRef]

24. Zheng, X.; Fan, Y.; Zhang, Y.Z. A novel energy-regenerative active suspension for vehicles. J. Shanghai Jiaotong Univ. Sci. 2008, 13, 184-188. [CrossRef]

25. Zheng, X.; Yu, F. Study on the potential benefits of an energy-regenerative active suspension for vehicles. SAE Trans. 2005, 114, 242-245.

26. Lin, X.; Bo, Y.; Xuexun, G.; Jun, Y. Simulation and performance evaluation of hydraulic transmission electromagnetic energy-regenerative active suspension. In Proceedings of the 2010 Second WRI Global Congress on Intelligent Systems (GCIS), Wuhan, China, 16-17 December 2010; Volume 3, pp. 58-61.

27. Tucker, C.; Wendell, R.; Anderson, Z.M.; Moen, E.; Schneider, J.; Jackowski, Z.M.; Morton, S. Integrated Energy Generating Damper. EP2582976 A2, 24 April 2013. 
28. Guo, K.; Zhang, Y.; Chen, Y.; Liu, Y. Active Pump Type Energy-Regenerative Damping System. CN103470672 A, 25 December 2013.

29. Fang, Z.; Guo, X.X. Energy Dissipation and Recovery of Vehicle Shock Absorbers. SAE Tech. Pap. 2012. [CrossRef]

30. Verros, G.; Natsiavas, S.; Papadimitriou, C. Design optimization of quarter-car models with passive and semi-active suspensions under random road excitation. J. Vib. Control 2005, 11, 581-606. [CrossRef]

31. Armstrong-Hélouvry, B.; Dupont, P.; De Wit, C.C. A survey of models, analysis tools and compensation methods for the control of machines with friction. Automatica 1994, 30, 1083-1138. [CrossRef]

32. Hamzehlouia, S.; Izadian, A.; Pusha, A.; Anwar, S. Controls of hydraulic wind power transfer. In Proceedings of the 37th Annual Conference on IEEE Industrial Electronics Society (IECON 2011), Melbourne, Australia, 7-10 November 2011; pp. 2475-2480.

33. Crowe, C.T.; Elger, D.F.; Roberson, J.A. Engineering Fluid Mechanics; Wiley: Hoboken, NJ, USA, 2005.

34. Franklin, G.F.; Powell, J.D.; Emami-Naeini, A. Feedback Control of Dynamic Systems; Pearson: London, UK, 2010.

35. Mossberg, J.; Anderson, Z.; Turker, C.; Schneider, J. Recovering Energy from Shock Absorber Motion on Heavy Duty Commercial Vehicles. SAE Tech. Pap. 2012. [CrossRef]

36. Wang, R.; Chen, Z.; Xu, H.; Schmidt, K.; Gu, F.; Ball, A.D. Modelling and validation of a regenerative shock absorber system. In Proceedings of the 20th International Conference on Automation and Computing (ICAC'14), Cranfield, UK, 12-13 September 2014; pp. 32-37.

37. ISO 8608:1995. Mechanical Vibration. Road Surface Profiles: Reporting of Measured Data; International Organization for Standardization: Geneva, Switzerland, 1996.

38. Pan, L.; Wu, L. A hybrid global optimization method for inverse estimation ofhydraulic parameters: Annealing-simplex method. Water Resour. Res. 1998, 34, 2261-2269. [CrossRef]

39. Backe, W.; Murrenhoff, H. Fundamentals of Hydraulic Oil Lecture Notes: Institute for Fluid Power Drives and Controls; RWTH Aachen University: Aachen, Germany, 1994.

40. Boes, C. Hydraulische Achsantriebe im Digitalen Regelkreis. Ph.D. Thesis, RWTH Aachen University, Aachen, Germany, 1995.

(C) 2016 by the authors; licensee MDPI, Basel, Switzerland. This article is an open access article distributed under the terms and conditions of the Creative Commons Attribution (CC-BY) license (http://creativecommons.org/licenses/by/4.0/). 